Research Article

\title{
Preservice Teachers' Learning to Respond on the Basis of Children's Mathematical Understanding
}

\author{
Mary Gichobi ${ }^{1}{ }^{1}$ and Alejandro Andreotti ${ }^{2}$ \\ ${ }^{1}$ UW-Green Bay, Green Bay, WI 54311, USA \\ ${ }^{2}$ Iowa State University, Ames, IA 50011, USA \\ Correspondence should be addressed to Mary Gichobi; mrnjoka1@gmail.com
}

Received 8 August 2018; Revised 9 March 2019; Accepted 10 April 2019; Published 2 May 2019

Academic Editor: Yi-Shun Wang

Copyright (c) 2019 Mary Gichobi and Alejandro Andreotti. This is an open access article distributed under the Creative Commons Attribution License, which permits unrestricted use, distribution, and reproduction in any medium, provided the original work is properly cited.

\begin{abstract}
This study examined the extent to which preservice teachers (PSTs) develop their capacity to attend to children's strategies and interpret and respond on the basis of children's mathematical understanding in the context of two well-designed assignments: Inquiry into Student Thinking assignment and tutoring assignment. The two assignments were assigned after 6 and 10 weeks of instruction, respectively. The analysis revealed that PSTs attended to children's strategies and interpreted children's mathematical understanding but struggled with the component skill of responding to children's mathematical understanding in the two assignments. Although the nature of tasks selected differed across the two assignments, generally PSTs focused on tasks that would develop children's mathematical understanding. The findings have theoretical implications for a hypothesized trajectory of professional noticing of children's mathematical understanding and the design of mathematics methods courses.
\end{abstract}

\section{Introduction}

The question of what preservice teachers (PSTs) can learn in teacher preparation programs to ensure that they are wellprepared beginning teachers of mathematics has increasingly drawn attention in the United States and around the world [1-7]. Specifically, the large-scale international study on mathematics teacher preparation (Teacher Education and Development Study-Learning to Teach Mathematics (TEDS-M)) conceptualized teachers' knowledge needed for teaching mathematics as consisting of mathematics content knowledge and mathematics pedagogical content knowledge [7]. Further, Association of Mathematics Teacher Educators (AMTE) [4] indicated that well-prepared beginning teachers of mathematics should possess robust knowledge of concepts and practices that they will encounter as beginning teachers and foundational understanding of students' mathematical knowledge.

Additionally, teacher educators have argued that lack of a common knowledge base, curriculum, or a common pedagogy in teacher preparation programs has made it challenging to study how content taught in teacher preparation courses supports PSTs to acquire the knowledge, practices, and skills required to effectively enact mathematics instruction as beginning teachers [8-13]. Some educators, e.g., $[8,12]$, have argued that developing a professional curriculum to prepare PSTs will require teacher educators to identify an approach that is focused on practice. Specifically, McDonald et al. [12] concluded that the new shift towards core practices "is an attempt to weave together novices' development of meaningful knowledge for teaching with their capacity to actually enact ambitious teaching ... in the classroom" (p. 379). However, although recent studies, e.g., [14-17], have explored some activities and teacher education pedagogies that are developing PSTs' knowledge and practices, the knowledge base is still in its infant stage and in need of further exploration.

This study examined the extent to which PSTs' capacity to respond on basis of children's mathematical understanding using two scaffolded assignments in the context of a mathematics methods course developed. Teachers' knowledge of children's mathematical understanding is part 
of what Shulman [18] defined as pedagogical content knowledge. Specifically, Shulman defined pedagogical content knowledge "as knowledge of ways of representing and explaining a subject to make it comprehensible, knowledge of students' thinking, and knowledge of the conceptions, preconceptions, and misconceptions students bring to the learning that make it easy or difficult to learn" (p. 25). In his description of pedagogical content knowledge, Shulman illuminated the need for teachers to understand children's thinking, arguing "teachers need knowledge of the strategies most likely to be fruitful in reorganizing the understanding of learners because those learners are unlikely to appear before them as clean blank slates" (p. 10). Similarly, Marks [19], as cited in Carpenter et al. [20], argued that teachers need knowledge of students' thinking which includes 'teachers' knowledge of (a) students' typical understanding, (b) students' learning process, (c) what is easy and hard for students, (d) the most common errors students make and, (e) particular students' understanding"(p. 12). Carpenter et al. [20] also argued that teachers' knowledge of students' thinking should provide a basis for understanding not only "what problems students can solve but also how they solve them" (p. 12). Carpenter and colleagues further argued that teacher's knowledge of students thinking provides a deeper understanding of how students learn for conceptual understanding.

In this article, the word "capacity" is used to refer to PSTs' ability to attend to children's strategies and interpret and respond based on children's mathematical understanding as conceptualized by [21]. Using the criteria identified by Ball et al. [8], one would argue that PSTs capacity to respond based on children's mathematical understanding is one of the "high leverage practices" that PSTs should learn as they go through a teacher preparation program because it is a practice that supports work that is central to mathematics. Ball et al. [8] identified the criteria of identifying high leverage practices as "(1) Supports work that is central to mathematics (2) Helps to improve the learning and achievement of all students (3) Is done frequently when teaching mathematics (4) Applies across different approaches to teaching mathematics" (p. 4). More recently, [4] emphasized the need to prepare beginning teachers with knowledge, skills, and dispositions that would equip them with foundational understandings of students' mathematical knowledge, skills, and dispositions. Additionally, PSTs should know how this foundational understanding can contribute to effective teaching and how they should be committed to expand and deepen their knowledge of students as learners of mathematics.

Furthermore, teachers' capacity to use children's mathematical understanding is fundamental and critical to effective teaching practice. A plethora of research findings have linked productive instructional environments to teachers' knowledge of how to teach elementary mathematics in a way that develops and relates to the benefit of attending to children's mathematical thinking [20, 22-25]. Consistent in these studies is teachers' use of Cognitively Guided Instruction (CGI), a framework that explicates how children's mathematical thinking develops and provides teachers with a context to interpret children's strategies, conceptions, and misconceptions in specific mathematical concepts. Cognitively Guided Instruction framework helps teachers understand children's thinking by constructing their own models of the development of how children think about specific content domains. Specifically, Franke and Kazemi [23] pointed out that teachers using CGI were well poised to engage in sense making around children's thinking, continually evaluated children's understanding, and adapted and built on children's mathematical thinking. These teachers also figured out how to make use of children's thinking in the context of their ongoing practice. Similarly, Fraivillig [26] examined how one first-grade teacher, Ms. Smith, engaged children in mathematical thinking and generated mathematical discussions in the classroom. What made Ms. Smith's instruction effective was "her ability to elicit children's solution methods, her capacity to support children's conceptual understanding, and her skill at extending children's mathematical thinking" (p. 2) [26]. Collectively, these studies have demonstrated that teachers who have more sophisticated understandings of children's thinking improve their teaching practices and are more likely to improve students' learning.

However, although the studies reviewed above suggest that focusing on children's mathematical thinking is a powerful mechanism for bringing pedagogy, mathematics, and students' understanding together, other research studies have suggested that the expertise of noticing, understanding, and using children's mathematical thinking to inform instructional decisions does not naturally develop [21, 23]. Specifically, Franke and Kazemi [23] argued "teachers listening to students' mathematical thinking generally struggled to make sense of the development of their students' mathematical thinking and how that related to their instructional decisions" (p. 4). Further, Jacobs et al. [21] developed a hypothetical trajectory, arguing that the expertise of attending to children's strategies and interpreting and deciding how to respond develop with teaching experience and engaging teachers in a professional development. In summary, the studies discussed in this section illuminate the need to purposefully develop teachers' (both in-service and PSTs') capacity to use children's mathematical thinking.

More recent studies have documented teacher educators' efforts to develop PSTs' ability to attend and interpret and respond on the basis of children's mathematical understanding [15-17, 27]. Specifically, McDuffie et al. [15] used repeated cycles of video viewing and guided reflection in different contexts as approximations, representations, and decomposition of teaching practice to develop PSTs' capacity to notice children's competencies [28]. The study examined the extent to which PSTs notice children's competencies related to children's mathematical thinking and children's community, culture, and linguistic. The video choices and opportunities to repeat the activity proved critical in developing PSTs' capacity to notice teacher moves, student thinking, and mathematics content and tasks. Teuscher et al. [17] explored how student teachers' journal entries evidenced their ability to notice students' mathematical thinking in the classroom. Similarly, Barnhart and Van Es 
[27] investigated how a video-based course supported secondary science PSTs in learning to analyze and reflect on teaching and learning in systematic ways. The findings revealed that PSTs who participated in the video-based course demonstrated higher sophistication overall in their attention and analysis and responses to students' thinking. This current study builds on these prior findings that have explicated PSTs' successes and struggles with responding on the basis of children's mathematical understanding using videos and journal entries. In this study, we used a case study as a representation of practice and provided PSTs with opportunities to replicate the representation of practice using the tutoring experience.

\section{Theoretical Framework}

The theoretical framework guiding this study is grounded in the notion of professional noticing of children's mathematical thinking [21, 29]. Mason [29] states that what professionals notice impacts what they learn with respect to their discipline. Research studies on teachers' professional noticing has focused on how teachers attend to students' thinking (noticing), how teachers interpret what they notice with respect to students mathematical understanding, and ultimately how those interpretations impact teachers' instructional practices [21,30-32]. Specifically, Sherin and Van Es [31] analyzed PSTs' narratives to explore the extent to which PSTs highlighted particular events that occurred, paid attention to specific or general evidence in the video, and took a descriptive, evaluative, and interpretive stance towards discussing what had occurred in the Video Analysis Support Tool (VAST) study. Furthermore, Van Es and Sherin [32] proposed that the skill of noticing includes (1) identifying what is important in a teaching situation, (2) drawing on one's knowledge of teaching and learning to reason about the situation, and (3) making connections between the specific classroom events and broader principles of teaching and learning. Jacobs et al. [21] conceptualized a hypothetical trajectory of teacher learning how to notice and interpret children's mathematical understanding as a set of three interrelated skills, namely, attending to children's strategies, interpreting children's understanding, and responding based on children's mathematical understandings. Figure 1 summarizes the key components of the hypothesized trajectory from the work of Sherin and Van Es and Jacobs and colleagues.

In addition, this study is informed by prior research that has focused on the extent to which teachers use what they notice to respond to children's mathematical understanding $[26,30]$. Jacobs and Ambrose [30] identified eight categories of intentional teacher moves that were productive in advancing mathematical conversations. Four of the moves were "supporting moves" that a teacher used before the children arrived at the correct answer while the other four were "extending moves" that a teacher can use after a child obtains the correct answer. The supporting move includes (1) ensuring that a child understands the problem, (2) change the mathematics to match the child's level of understanding, (3) explore what the child has already done, and
(4) remind the child to use other strategies. The extending moves include (1) promoting reflection on a strategy that is just completed, (2) encourage the child to explore multiple strategies and their connections, (3) connect the child's thinking to symbolic notation, and (4) generate follow-up problems or select the next problem. These moves had similarities with [26] framework of advancing children's mathematical thinking since the two approaches presented teachers' actions in a continuum of eliciting children's solutions, supporting children's understanding to extending children's mathematical thinking. Informed by Jacobs and Ambrose [30], this current study focuses on how PSTs use what they notice to plan for instructional session. Specifically, this study focuses on how PSTs generate or select follow-up problems based on children's mathematical understanding.

\section{Purpose of the Study}

This study examined PSTs' capacity to respond based on children's mathematical understanding using two scaffolded assignments in the context of a mathematics methods course, by investigating three research questions:

(1) To what extent do PSTs develop the capacity to attend to children's strategies, interpret, and respond based on children's mathematical understanding in the context of scaffolded activities?

(2) To what extent is the rationale of the PSTs' choices of instructional tasks based on children's mathematical understanding?

(3) What type of tasks/problems do PSTs pose after assessing children's mathematical understanding?

In this study, we used the nature of tasks/problems that PSTs selected and designed as they completed the two assignments as a lens to understand their ability to respond based on children's mathematical understanding. We analyzed PSTs' capacity to respond based on children's mathematical understanding in the context of scaffolded activities in a mathematics methods course. Scaffolds have been described as structures, tools, and assistance from more knowledgeable others that allow learners to engage in practices beyond their independent capacity [33-35]. Consequently, scaffolding has been used in teacher preparation programs to support PSTs' learning to do the work of teaching and has been found to have impact on PSTs' learning $[33,36,37]$. In this study, we conceptualize scaffolding as a combination of "an act of teaching" [38] and a set of activities designed to provide PSTs with targeted support to develop their capacity to use children's mathematical understanding. Holton and Clarke [38] argued that an act of teaching should "(1) support the immediate construction of knowledge by the learner and (2) provide the basis for the future independent learning of the individual" (p. 6). In this study, the scaffolds were in the form of classroom discussions, minor homework activities with specific prompts, viewing targeted video clips, and major assignments with prompts similar to the ones in the minor 


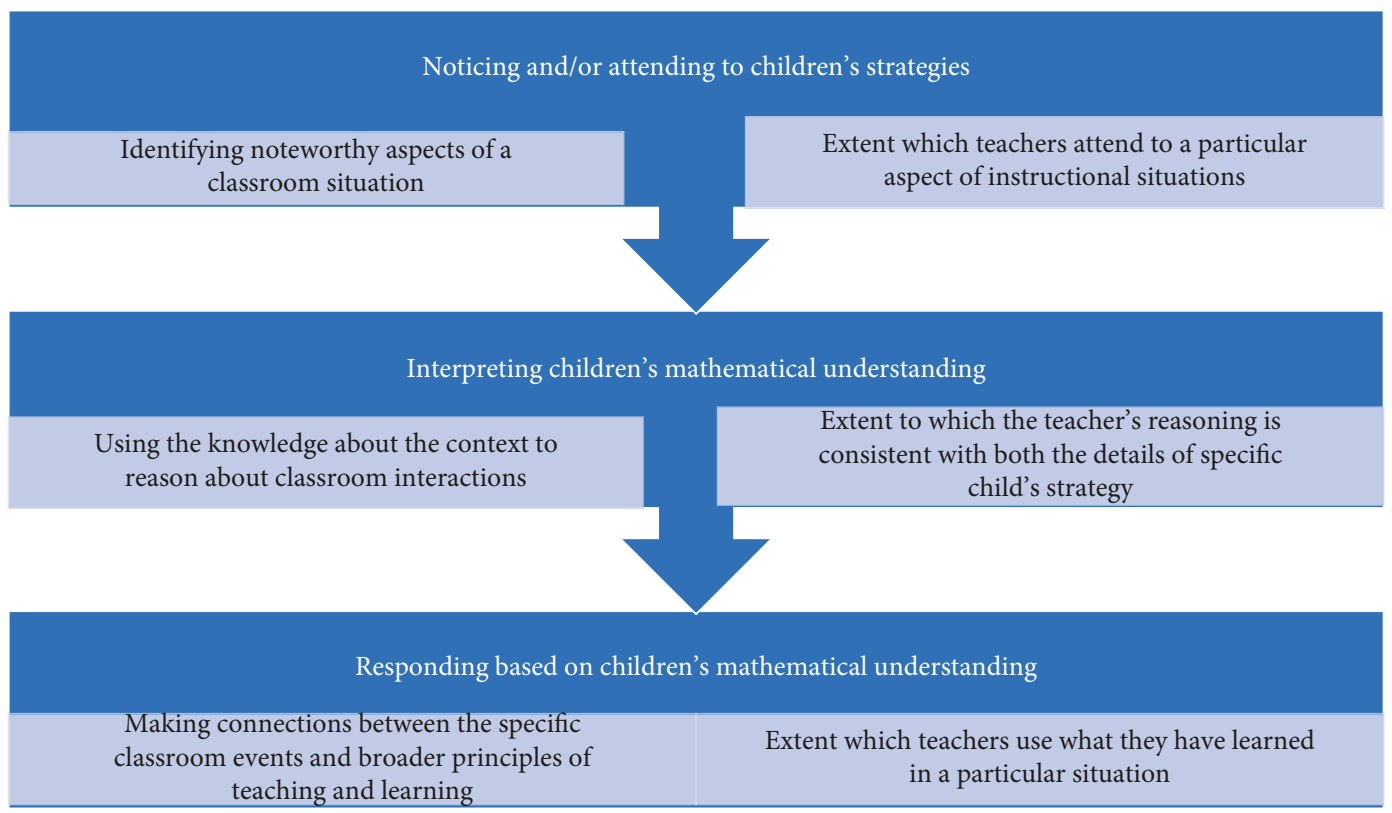

Figure 1: Summary of the hypothesized developmental trajectory of professional teacher noticing.

homework activities to provide PSTs with multiple opportunities to perform the same skill over time. As Tabak [39] argued, the goal in multiple scaffolds is to provide different supports using different modalities that are sequenced at different times in the curriculum. We expected the sequenced tasks to support PSTs' construction of knowledge. One would argue that the classroom discussions were used as opportunities for "decomposition of practice", videos were used as "the representation of practice," and the minor and major assignments were used as "approximations of practice" where PSTs practiced how to respond based on children's mathematical understanding [28].

\section{Methodology}

This is a qualitative interpretive study that was conducted in the context of a mathematics methods course in a large university in the United States. Two scaffolded assignments that were completed at two different times as the PSTs progressed through the course were used as a source of data. In the Inquiry into Student Thinking assignment, PSTs analyzed the mathematical understanding of one child from a case study of four children (Appendix A.1). In the tutoring assignment, PSTs interviewed two to three children from a nearby elementary school and then planned for a series of four tutoring sessions (Appendix A.2). We chose to explore the practices of attending to children's strategies and interpreting and responding based on children's mathematical understanding in the context of scaffolded assignment because these practices include activities that are essential to the work of teaching [8].

4.1. Course Content. The elementary mathematics methods course met for three hours each week over a 14-week semester. The course met in the university classroom for
6 weeks, followed by a clinical experience of 6 weeks in a K-8 classroom. For the last two weeks of the semester, they met in a university classroom to debrief the practicum experience. The stated primary goal of the course was to develop PSTs' capacity to design and implement mathematics instruction that is both reflective and mathematically significant. The course was organized around four learning goals:

(i) How children's thinking typically develops, including common understanding, misunderstanding, strategies, and errors

(ii) How to access and assess children's mathematical thinking within different content areas

(iii) How to use children's mathematical thinking to select and pose worthwhile mathematical tasks

(iv) How to use curriculum materials, family, and community resources and other supports to help the PSTs facilitate the development of children's mathematical thinking

To meet these goals, the course was built around a variety of in class activities and homework assignments contained in a course packet developed by the mathematics education team at the university. These activities included using video clips, analyzing children's written work, and developing and solving CGI problem types.

4.2. Participants and Data Sources. All the participants were enrolled in a two-year teacher education program as part of their four-year undergraduate degree. Fifty-six PSTs from three different sections of the methods course consented to participate in the study at the beginning of the semester, but only data from thirty participants were used because those were the participants for whom researchers had access to all their course work activities and reflections. While analyzing 
the data, we noted that some PSTs had not submitted some of the assignment or they submitted in a format that was not accessible. For every participant, copies of written work (the original work was returned to the students) with responses to the Inquiry into Student Thinking assignment, the tutoring assignment and any work related to the course across the semester was collected. In the next section, the expectations of these course assignments and their purpose are briefly elaborated.

4.3. Inquiry into Student Thinking Assignment. For this assignment, the primary source of information was found in a case study of four second graders described in [40]. The case study reflections were developed by Susan Empson at the University of Texas at Austin, after working for 10 weeks with four second graders who had difficulties in math. PSTs read through the case study and wrote a detailed 2-3-page reflection using the prompts in Table 1. PSTs' responses for this assignment were used to examine their capacity to attend to children's strategies and interpret and respond based on children's mathematical understanding.

4.4. Tutoring Assignment. The tutoring assignment is a fieldbased assignment completed in three $\mathrm{K}-4^{\text {th }}$ grade elementary classrooms. PSTs were expected to plan for instruction based upon knowledge of subject matter, students, community, curriculum goals, and state curriculum models. To complete the assignment, PSTs interviewed elementary level students about their understanding of number and operations and problem solving. Based on their interpretation of the interview responses, PSTs planned and implemented three tutoring sessions using tasks that were challenging and yet accessible to the students. During the final session, they interviewed the student(s) again to assess their mathematical understanding after the three tutoring sessions. The activity was completed in four 50-minute sessions over a period of one month. For each session, PSTs responded to the prompts in Table 1.

\section{Data Analysis and Coding}

Data analysis used quantitative and a qualitative interpretive research approach [41-43]. As Walsham [43] indicated, interpretive researchers report the interpretation and the meaning assigned to specific phenomenon by other people. They focus on analytically disclosing those meaning-making practices, while showing how those practices configure to generate observable outcomes. The sharable results in interpretive research should be in form of development of concepts, generation of theory, drawing specific implications, and contribution of rich insights. In this study, PSTs' responses to the two assignments were considered for evidence of attending to children's strategies and interpreting and responding based on children's mathematical understanding. A coding scheme was developed based on the literature review about what and how teachers notice children's mathematical understanding $[21,31,32]$. As described in the next section, every component skill of professional noticing of children's mathematical thinking was coded, and the responses quantified to foster meaningful comparisons and allow patterns to be identified [44].

\subsection{Coding}

5.1.1. Attending to Children's Strategies. For the component skill of attending to children's strategy, we considered the extent to which PSTs' explanation demonstrated evidence of providing mathematical details. A code of most mathematical details was used for responses providing detailed explanation of the children's strategy and some mathematical details for responses where the PSTs provided only some details about the strategy. For some mathematical details, PSTs did not provide substantial mathematical details on how the child solved any specific task but provided a general description with no specific details on how the child did the task. For the code lack of mathematical details, PSTs did not identify the strategy and/or did not provide any mathematical details on how the children solved a specific task. As shown in Table 2, this coding scheme was used for both the Inquiry into Student Thinking and tutoring assignment.

\subsubsection{Interpreting Children's Mathematical Understanding.} Due to the nature of the prompts given in the two assignments, the first glimpse of data analysis revealed that most PSTs took an interpretive stance rather than descriptive or evaluative stance [31]. We decided to code the extent which the PSTs' interpretation of children's mathematical understanding was consistent with the details of the specific children's strategies. Therefore, the codes robust evidence, limited evidence, and lack of evidence were used to examine PSTs' responses. As shown in Table 3, a response was coded to have robust evidence if the PST made sense of details of children's strategy and noted how the details reflected children's understanding. A response was coded as limited evidence if they focused on children's mathematical understanding, but their responses did not have in-depth interpretation like the robust evidence. In these responses, the participants interpreted children's mathematical understanding but with broader undefined terms. Also, connections to children's strategies were overgeneralized and often did not provide specific evidence on how the children did the task. Finally, a response was coded as lack of evidence if the response did not provide any evidence of interpreting children's mathematical understanding even though they had been prompted to do so.

\subsubsection{Responding Based on Children's Mathematical} Understanding. Similar to Jacobs et al. [21], PSTs' explanations and rationale of their intended choice of instructional task in the Inquiry into Student Thinking assignment were coded as either having robust evidence, limited evidence, or lack of any evidence that the choice of the next instructional task was based on children's mathematical understanding. As shown in Table 4, a response was coded to 
TABLE 1: Summary of prompts used in the two assignments.

\begin{tabular}{|c|c|c|}
\hline Component skill & Inquiry into Student Thinking & Tutoring assignment \\
\hline Attending to children's strategy & $\begin{array}{l}\text { (i) Choose one of the four students from the } \\
\text { case study and trace their responses and } \\
\text { learning through the study. } \\
\text { (ii) Summarize what you think they knew or } \\
\text { understood at the end of the study that they } \\
\text { did not know or understand in the beginning } \\
\text { (iii) Choose } 2 \text { examples of this student's } \\
\text { responses as evidence for your claim from } \\
\text { part (1) and explain how they support your } \\
\text { claim about this student's learning. }\end{array}$ & $\begin{array}{c}\text { What does each student know, think, and } \\
\text { understand about number, operations, and } \\
\text { problem solving? }\end{array}$ \\
\hline $\begin{array}{l}\text { Interpreting children's mathematical } \\
\text { understanding }\end{array}$ & $\begin{array}{l}\text { (i) Summarize what you think they knew or } \\
\text { understood at the end of the study that they } \\
\text { did not know or understand in the beginning } \\
\text { (ii) Choose } 2 \text { examples of this student's } \\
\text { responses as evidence for your claim from } \\
\text { part and explain how they support your } \\
\text { claim about this student's learning. }\end{array}$ & $\begin{array}{c}\text { How will what you learned in the interviews } \\
\text { influence how you work with the children } \\
\text { during the next sessions? }\end{array}$ \\
\hline $\begin{array}{l}\text { Respond based on children's mathematical } \\
\text { understanding }\end{array}$ & $\begin{array}{l}\text { (i) If you were to teach the next lesson to this } \\
\text { group of students, write one problem that } \\
\text { you could give them and explain why you } \\
\text { think this would be a good problem for this } \\
\text { group }\end{array}$ & $\begin{array}{l}\text { How are these tasks intended to build on } \\
\text { what you know about your students' } \\
\text { understanding and misunderstanding? }\end{array}$ \\
\hline
\end{tabular}

TABle 2: Examples of responses coded as most, some, and lack of mathematical details.

\begin{tabular}{|c|c|c|}
\hline Code & Inquiry into Student Thinking & Tutoring assignment \\
\hline Most mathematical details & $\begin{array}{l}\text { He solved it with a direct modeling procedure and } \\
\text { drew each individual soccer ball in the designated } \\
\text { three bags. Emilio worked on the problem: Dr. E has } \\
4 \text { rolls of candy and } 11 \text { loose candies. How many } \\
\text { candies does she have altogether? He initially spat } \\
\text { out the number } 40 \text { and explained on his own that } \\
\text { there were candies in each of the four rolls. He had } \\
\text { trouble counting up from } 40 \text { to } 51 \text { for the } 11 \text { single } \\
\text { candies, but this is an issue he had the first day as } \\
\text { well and shows that may be another issue. However, } \\
\text { because he knew to count up from } 40 \text { by } 1 \text { single } \\
\text { candies shows that he is able to distinguish groups of } \\
51 \text { from single units which is very significant in using }\end{array}$ & $\begin{array}{l}\text { On the JRU problems, Tyler would use a breaking- } \\
\text { the-number-apart strategy. He would like to get the } \\
\text { numbers into base } 10 \text { so that they would be easier } \\
\text { to add together. For example, on the first set of } \\
\text { numbers }(42,36) \text { for the apples problem, Tyler told } \\
\text { me that the answer was } 78 \text {. When I asked how he } \\
\text { knew that he wrote out that } 42+30=72 \text { and then } \\
\text { wrote } 72+6=78 \text {. I was really excited that he knew } \\
\text { a shortcut for how to do the problem. He also used } \\
\text { this same strategy for the SRU problems. }\end{array}$ \\
\hline
\end{tabular}

51 from single units which is very significant in using base ten problem-solving strategies.

\begin{tabular}{|c|c|c|}
\hline Some mathematical details & $\begin{array}{l}\text { Jack throughout the case study counted up by ones } \\
\text { to find his answer. From the very first day, Jack } \\
\text { miscounted the total number of soccer balls } \\
\text { because he had the wrong number of soccer balls in } \\
\text { one bag, even though all of the bags had simply } 10 \\
\text { balls in each. In his first few sessions, Jack tended to } \\
\text { write tall marks to keep track of whatever he was } \\
\text { counting, no matter how big the number was. }\end{array}$ & $\begin{array}{l}\text { Apple problem: The student started with the } \\
\text { original amount of blocks ( } 3 \text { ) then found the } \\
\text { number of picked apples (12). After this the student } \\
\text { started counting the blocks starting with } 3 \text {, } \\
\text { counting up to } 12 \text { on, starting with } 3,4,5,6,7,8,8 \text {, } \\
10, \ldots \text { This led me to doing a problem that would } \\
\text { include counting since my goal for the lesson was } \\
\text { to get my student to be able to count in sequence } \\
\text { starting from a given number in the known } \\
\text { sequence. }\end{array}$ \\
\hline Lack of any mathematical details & $\begin{array}{l}\text { In the beginning, Jack did not recognize ten as a } \\
\text { numerical unit. It seemed that, to him } 10 \text { was no } \\
\text { different than } 4 \text { or } 9 \text {. Because of this, he often } \\
\text { counted up to the answer. As the study went on, he } \\
\text { began to develop an understanding of ten, first by } \\
\text { using a representation of } 10 \text { (rather than tally marks } \\
\text { or other such one-to-one representations) in session } \\
5 \text { and later by solving number sentences by counting } \\
\text { tens rather than counting up by ones (seen in session } \\
9 \text {, but also hinted at from session } 5 \text { on. }\end{array}$ & $\begin{array}{l}\text { Second, any straightforward problem (e.g., } \\
23+57=\ldots \text { ) was not difficult for them. It did not } \\
\text { seem to matter whether a task was JSU, SCU, SIU } \\
\text { or SRU; those sorts of problems were simply too } \\
\text { easy for these three students unless the numbers } \\
\text { were sufficiently large enough to require them to } \\
\text { use paper just to keep track of their carrying ... }\end{array}$ \\
\hline
\end{tabular}

Note: Join Result Unknown (JRU) Join Change Unknown (JCU) Join Initial Unknown (JIU) Separate Result Unknown (SRU) Separate Change Unknown (SCU) Separate Initial Unknown (SIU). 
Table 3: Examples of responses coded as robust, limited, and lack of evidence.

\begin{tabular}{|c|c|}
\hline Code & Inquiry into Student Thinking-interpretation \\
\hline Robust evidence & $\begin{array}{l}\text { I believe that Jack, by the end of the study, had a much } \\
\text { better understanding of how to use his knowledge of } \\
\text { base ten in solving problems } \\
\text { One of the problems was this: (JCU) } 22 \text { pennies, how } \\
\text { many more to have } 50 \text {. Jack solved this problem by } \\
\text { counting up by ones from } 22 \text { using tallies to keep track, } \\
\text { which solves the problem but shows evidence that he } \\
\text { does not fully understand how to use his base ten } \\
\text { knowledge to help solve problems. In session ten they } \\
\text { did a problem that was as follows: } 30 \text { pencils, } 29 \text { more. } \\
\text { This is a somewhat similar problem from the one in } \\
\text { example } 1 \text {. For both he needed to count up by about } 30 \\
\text { to get the answer; but this time to solve the problem he } \\
\text { drew a picture that represented groups of tens and then } \\
\text { ones. This time he did use his knowledge of base ten to } \\
\text { help make this problem easier to solve. }\end{array}$ \\
\hline
\end{tabular}

10 have now become a unit for Jack instead of just the 1's

I think both Calvin and Karl seemed to have a good understanding of numbers when counting forward and backward by rote memory. They were able to answer all the questions with ease. I even tried using some of the second-grade questions and they were able to answer them without even thinking.

Jack didn't have an understanding of base ten at the beginning of the case study but, by the end, he had a concrete understanding of the base ten process. At first Jack got confused with the terminology of loose and thought that he should subtract the balls instead of adding the balls together and he misunderstood the problem type. By the end of the case study, Jack had a better understanding of how to decode problems Tutoring assignment-interpretation

Brian had a good understanding of base 10 and basic problems. He was able to count very well and almost never stumbles when switching decades, e.g., 97, 98, $99,100,101, \ldots$ He also demonstrated that he was capable of counting by 10 s both forward and backward. I was especially happy to see him easily counting backwards, 204, 195, 184, 174, etc. Brian also understand the use of the equal sign ...

Lack of any evidence more properly.

have robust evidence if there was evidence that the choice of task was based on children's mathematical understanding. In other words, the participant considered children's understanding as reflected in particular strategy used and how the next task could further extend the specific children's understanding. In some cases, the participants anticipated the alternative strategies that the children could use and how the task would build on existing children's understanding. Likewise, coding was performed for the learning goals, explanations, and rationale of selecting the specific tasks in the tutoring assignment after PSTs conducted the initial interview. We used the code lack of evidence for responses that provided no evidence of responding based on children's mathematical understanding. These responses did not reference prior children's mathematical understanding or how the task would extend children's mathematical understanding. In some cases, the responses were characterized by participants who wanted to give children harder tasks, reevaluate children's mathematical understanding, or continue practicing what they had already learned. Sometimes, the participant did not provide any rationale.

After coding the PSTs' responses for each component skill, we quantified the data in order to foster more meaningful comparisons and allow patterns to be identified and further explored $[44,45]$. As shown in Table 5, we assigned a value of " 2 " to responses that were coded to have most mathematical details, a value of " 1 " to responses that were coded to have some mathematical details, and " 0 " to responses that were coded to have no mathematical details for the component skill of attending to children's strategies. Similarly, we assigned a value of " 2 " to any response with robust evidence, a value of " 1 " to any response with limited evidence, and a value of " 0 " to any response with lack of any evidence, both for the component skill of interpreting and responding based on children's mathematical understanding.

Using the coded values, calculations of the number of PSTs' responses that had most, some, or lack of any mathematical details as they attended to children's strategies were performed. Similarly, calculations of PSTs' responses with robust, limited, or lack of any evidence that they interpreted and/or responded on the basis of children's mathematical understanding were performed during the two assignments. Further, we conducted a paired sample $t$-test to determine whether differences in the number of PSTs' performance in the three component skills of professional noticing of children's mathematical thinking in the two assignments were statistically significant. This first stage of data analysis helped identify patterns that were consistent across the two assignments.

To examine the nature of tasks that PSTs posed after assessing children's mathematical understanding, data from 
TABle 4: Examples of responses coded as robust, limited, and lack of evidence.

\begin{tabular}{|c|c|c|c|c|}
\hline Code & $\begin{array}{l}\text { Inquiry into Student } \\
\text { Thinking-selected task }\end{array}$ & Rationale & $\begin{array}{c}\text { Tutoring } \\
\text { assignment-selected task }\end{array}$ & Rationale \\
\hline $\begin{array}{l}\text { Robust } \\
\text { evidence }\end{array}$ & $\begin{array}{l}\text { I would create Joint-Result- } \\
\text { Unknown (JRU) or Separate- } \\
\text { Result-Unknown (SRU) } \\
\text { problems for the students. A } \\
\text { JRU example would be } \\
\text { "Sunny has fish, and } \\
\text { then she buys more. } \\
\text { How many fish does she have } \\
\text { now?" Number choices } \\
\text { would include }\{(10,50)(20 \text {, } \\
\text { 30) }(10,41)(15,25)\} \text {. }\end{array}$ & $\begin{array}{l}\text { This type of problem would } \\
\text { be good for all of the students. } \\
\text { Sunny and Daniella struggle } \\
\text { to count by tens past the } \\
\text { numbers } 20 \text { and } 30 \text {, and this } \\
\text { problem challenges them to } \\
\text { do so. Emilio would be } \\
\text { challenged to count by tens } \\
\text { and keep track of the 'one' in } \\
41 \text {. Both Jack and Emilio } \\
\text { would be challenged by the } \\
\text { last number choice, as both } \\
\text { understand the concept of } \\
\text { counting by tens, but they } \\
\text { would have to extend their } \\
\text { understanding to non-zero } \\
\text { ending numbers. }\end{array}$ & $\begin{array}{l}\text { Cornor has _ Wii games in } \\
\text { his cupboard. He found } \\
\text { more Wii games under } \\
\text { his bed. How many Wii } \\
\text { games does Cornor have? } \\
\text { Number Choices: }(7,3)(4,6) \\
\text { James has_ Wii games at } \\
\text { his house. Cornor let James } \\
\text { borrow __more Wii games. } \\
\text { How many Wii games does } \\
\text { James have at his house now? } \\
\text { Number choices: }(5,5)(2,8)\end{array}$ & $\begin{array}{l}\text { After my initial interview } \\
\text { with the students, I knew they } \\
\text { did not have a clear } \\
\text { understanding on how to } \\
\text { count on from a number } \\
\text { other than one. When I gave } \\
\text { each student that question in } \\
\text { the interview none could } \\
\text { count on from the number I } \\
\text { had given them ... } \\
\text { I chose to do a Joint Result } \\
\text { Unknown story problem } \\
\text { because I wanted the } \\
\text { problems to begin with a } \\
\text { number other than } 1\end{array}$ \\
\hline $\begin{array}{l}\text { Limited } \\
\text { evidence }\end{array}$ & $\begin{array}{c}\text { If Quinn had } 89 \text { pieces of } \\
\text { pizza, and } 10 \text { pieces of pizza } \\
\text { made a whole pizza, how } \\
\text { many whole pizzas can Quinn } \\
\text { make? }\end{array}$ & $\begin{array}{l}\text { This is a Separate Result } \\
\text { Unknown problem. I chose } 89 \\
\text { because the students have the } \\
\text { concept of base } 10 \text { down; they } \\
\text { are able to do it with the easy } \\
\text { numbers, now I want to } \\
\text { challenge them with bigger } \\
\text { numbers, hoping they would } \\
\text { use the manipulative[s] and } \\
\text { not their fingers. I would hope } \\
\text { students could lay out the } \\
\text { manipulative[s] and see easily } \\
\text { that they can make } 8 \text { pizzas. If } \\
\text { students understand this } \\
\text { concept they should have no } \\
\text { problem with this problem. }\end{array}$ & $\begin{array}{l}\text { The student will be given } \\
\text { visual balance with numbers } \\
\text { in blocks. One black on the } \\
\text { right side will be blank. My } \\
\text { number choices are } 6 \text { and } 2 \\
\text { on the left sides and a blank } \\
\text { and } 4 \text { on the right side }\end{array}$ & $\begin{array}{l}\text { I plan to work on commutative } \\
\text { property and relational } \\
\text { thinking to help with those } \\
\text { problems. Latter I plan to } \\
\text { focus on his subtraction skills } \\
\text { so that he will be willing to use } \\
\text { them in other problems ... } \\
\text { The purpose of this exercise } \\
\text { was to have Mathew begin } \\
\text { thinking in terms of something } \\
\text { balancing or equaling } \\
\text { something else in a horizontal } \\
\text { format. The balance scale is } \\
\text { meant to be a visual tool to } \\
\text { eventually lead to } \\
\text { understanding of number } \\
\text { sentences. }\end{array}$ \\
\hline
\end{tabular}

I choose this Separate Result

Unknown problem because I wanted the students to continue using addition. The student will be presented

If I were to teach the next lesson to these students, one problem I could give them would be a: Jack has 45

Lack of any evidence crackers. Sunny gives him 10 more. How many crackers does Jack have?
These are the problems they have been used to and need to keep getting trying to understand. I chose the numbers 45 and 10 because the students need to continue using large numbers so they can't just count by ones and learn to use going by 5's or 10 's as a first choice. with these problems one at a time and they determine whether the problem is true

$$
\begin{gathered}
\text { or not. } \\
4+2=6 \\
3+3=6 \\
4+2=3+3
\end{gathered}
$$

These equations allow the student to look at the two different equations and see that although the numbers are different they equal the same thing.
PSTs' responses to the last two prompts given in the Inquiry into Student Thinking assignment and the tutoring assignment were used:

(i) If you were to teach the next lesson to this group of students, write one problem that you could give them and explain why you think this would be a good problem for this group (ii) How are these tasks intended to build on what you know about your students' understanding and misunderstanding?

In this stage of data analysis, open coding was performed to make meaning of the PSTs' conceptions and rationale of tasks that would engage students with either high-level or low-level thinking using the levels of cognitive demand 
TABLe 5: Description of the coding scheme.

\begin{tabular}{lccc}
\hline Component skill & Code & Subcode & Score \\
\hline Attending to children's strategies & $\begin{array}{c}\text { Considers the extent to which PSTs' explanation } \\
\text { demonstrated evidence of providing } \\
\text { mathematical details }\end{array}$ & $\begin{array}{c}\text { Most mathematical details } \\
\text { Some mathematical details } \\
\text { Lack of mathematical } \\
\text { details }\end{array}$ & $\begin{array}{c}1 \\
0\end{array}$ \\
\hline $\begin{array}{l}\text { Interpreting children's mathematical } \\
\text { understanding }\end{array}$ & $\begin{array}{c}\text { Considers the extent to which PSTs' explanations } \\
\text { demonstrated evidence that the interpretation was }\end{array}$ & $\begin{array}{c}\text { Robust evidence } \\
\text { Limited evidence }\end{array}$ & 2 \\
back of evidence & 0 \\
\hline $\begin{array}{l}\text { Responding based on children's mathematical children's mathematical understanding } \\
\text { understanding }\end{array}$ & $\begin{array}{c}\text { Considers the extent to which PSTs' rationale } \\
\text { demonstrated evidence that it was based on } \\
\text { children's mathematical understanding }\end{array}$ & $\begin{array}{c}\text { Robust evidence } \\
\text { Limited evidence } \\
\text { Lack of evidence }\end{array}$ & $\begin{array}{l}2 \\
1\end{array}$ \\
\hline
\end{tabular}

described by work done by Stein and Smith [46, 47]. PSTs' rationale of selecting tasks was scrutinized for evidence or lack there off of responding on the basis of children's mathematical understanding. Common themes suggestive of their conceptions were identified and coded using the three themes, namely, considering what the children will do as they engage with the mathematical idea, considering what the teacher will do when enacting the task, and no rationale for choosing the task.

To measure reliability and validity, an independent member check was used [48]. The first author developed the coding scheme and coded the data and the second author coded half of the responses sampled for this study. Ninety percent (90\%) consensus was achieved, and discrepancies were discussed and agreed upon based on the calculated agreement score. A third coder who is knowledgeable in mathematics education verified the responses that were coded under each category to ensure that the codes represented the description of the coding scheme. This verification process of the coding scheme allowed the first author to obtain feedback on the coding scheme, emergent patterns, and interpretations, thereby increasing the credibility of the assertions in the study.

\section{Findings and Results}

This section presents the results organized in the following subtopics: (a) extent to which PSTs attended to children's strategies, (b) extent to which PSTs interpreted children's mathematical understanding, (c) extent to which PSTs responded based on children's mathematical understanding, (d) outcome of the paired $t$-test, and (e) the nature of the tasks selected and PSTs' understanding of tasks that would engage students with high-level thinking.

6.1. Attending to Children's Strategies. As shown in Table 6, the Inquiry into Student Thinking assignment responses provided evidence that most PSTs had the capacity to attend to children's strategies after six weeks of instruction. Specifically, $40 \%$ of PSTs' responses were categorized as having most mathematical details, $56.7 \%$ responses had some mathematical details, and 3.3\% responses had provided no mathematical details and hence no evidence of attending to children's strategies.
Similarly, analysis of PSTs' responses in the tutoring assignment revealed that $73.3 \%$ of PSTs' responses demonstrated evidence of attending to children's strategies by providing most mathematical details as compared to $26.3 \%$ PSTs' responses that demonstrated some or no mathematical details.

A closer look at PSTs' responses revealed that out of the twenty-two PSTs whose responses demonstrated evidence of providing most mathematical details during the tutoring assignment, nine had previously provided most mathematical details during the Inquiry into Student Thinking assignment. The remaining eleven participants provided some mathematical details in the Inquiry into Student Thinking assignment, and their responses during the tutoring assignment had evidence that they provided most mathematical details. These results indicate that the eleven PSTs' performance shifted from general descriptions of children's strategies to providing details of children's strategies and including details on how the children interacted with the mathematical ideas.

6.2. Interpreting Children's Mathematical Understanding. Analysis shows that $60 \%$ of participants' responses demonstrated robust evidence, while $33.3 \%$ demonstrated limited evidence that they interpreted children's mathematical understanding in the Inquiry into Student Thinking responses. Only $6.7 \%$ of participants' responses demonstrated no evidence that they made sense of details of children's strategies when interpreting children's mathematical understanding. In the tutoring assignment, analysis revealed that $70 \%$ of the PSTs' responses demonstrated robust evidence and $23.3 \%$ of the PSTs' responses demonstrated limited evidence that they made sense of details of children's strategies as they interpreted children's mathematical understanding. Only $6.7 \%$ of the responses demonstrated no evidence that the participants made sense of children's mathematical strategies.

Furthermore, detailed analysis of individual PST responses revealed patterns that represented their performance in the component skill of interpreting based on children's mathematical understanding. For example, the number of PSTs (18 out of 30) whose responses had robust evidence in the Inquiry into Student Thinking assignment that they interpreted children's mathematical understanding 
TABLE 6: Summary of PSTs' responses in the two assignments.

\begin{tabular}{|c|c|c|c|c|}
\hline Component skill & $\begin{array}{c}\text { Inquiry into Student } \\
\text { Thinking }\end{array}$ & $\begin{array}{l}\% \text { \# of PSTs } \\
\text { responses }\end{array}$ & Tutoring assignment & $\begin{array}{l}\% \text { \# of PSTs' } \\
\text { responses }\end{array}$ \\
\hline \multirow{3}{*}{ Attending to children's strategies } & Most mathematical details & $40 \%(N=12)$ & \multirow{2}{*}{$\begin{array}{l}\text { Most mathematical details } \\
\text { Some mathematical } \\
\text { details }\end{array}$} & $73.3 \%(N=22)$ \\
\hline & $\begin{array}{l}\text { Some mathematical } \\
\text { details }\end{array}$ & $56.7 \%(N=17)$ & & $23.3 \%(N=7)$ \\
\hline & $\begin{array}{c}\text { Lack of any mathematical } \\
\text { details }\end{array}$ & $3.3 \%(N=1)$ & $\begin{array}{c}\text { Lack of any mathematical } \\
\text { details }\end{array}$ & $3.3 \%(N=1)$ \\
\hline \multirow{3}{*}{$\begin{array}{l}\text { Interpreting Children's mathematical } \\
\text { understanding }\end{array}$} & Robust evidence & $60 \%(N=18)$ & Robust evidence & $70 \%(N=21)$ \\
\hline & Limited evidence & $33.3 \%(N=10)$ & Limited evidence & $23.3 \%(N=7)$ \\
\hline & Lack of evidence & $6.7 \%(N=2)$ & Lack of evidence & $6.7 \%(N=2)$ \\
\hline \multirow{3}{*}{$\begin{array}{l}\text { Responding based on children's } \\
\text { mathematical understanding }\end{array}$} & Robust evidence & $13.3 \%(N=4)$ & Robust evidence & $36.7 \%(N=11)$ \\
\hline & Limited evidence & $60 \%(N=18)$ & Limited evidence & $33.3 \%(N=10)$ \\
\hline & Lack of evidence & $26.7 \%(N=8)$ & Lack of evidence & $30.0 \%(N=9)$ \\
\hline
\end{tabular}

was larger than the number of PSTs (12 out of 30) whose responses had most mathematical details. Specifically, nine out of the 18 PSTs' responses demonstrated evidence of providing most mathematical details and demonstrated robust evidence that their interpretation was based on children's mathematical understanding. The remaining nine participants' demonstrated evidence of providing some mathematical details in the component skill of attending to children's strategies but their responses had robust evidence that their interpretation was based on children's mathematical understanding.

Similarly, the ten responses that had limited evidence that the PSTs' interpretation was based on children's mathematical understanding in the Inquiry into Student Thinking varied in their performance in the component skill of attending to children's strategies. Three of them had provided most mathematical details in the component skill of attending to children's strategy, but their responses had limited evidence that their interpretation was based on children's mathematical understanding. Seven of the participants only provided some mathematical details in the component skill of attending to children's strategies, but their responses had limited evidence that their interpretation was based on children's mathematical understanding.

6.3. Responding Based on Children's Mathematical Understanding. For the component skill of responding based on children's mathematical understanding, only $13.3 \%$ of the participants' responses demonstrated robust evidence that the responses were based on children's mathematical understanding in the Inquiry into Student Thinking. In comparison with the other component skills, few PSTs seemed to have demonstrated robust evidence of responding based on children's mathematical understanding. Most PSTs (60\%) demonstrated limited evidence that their responses were based on children's mathematical understanding while $26.7 \%$ of participants' responses lacked any evidence that they were based on children's mathematical understanding. In the tutoring assignment, only $36.7 \%$ of the responses demonstrated robust evidence that PSTs' responses were based on children's mathematical understanding and $33.3 \%$ of the responses demonstrated limited evidence that PSTs' responses were based on children's mathematical understanding.
Further analysis revealed that $30 \%$ of PSTs' responses demonstrated no evidence that their responses were based on children's mathematical understanding. The results indicate that PSTs struggled more with the component skill of responding during the two assignments than with the component skills of attending and interpreting children's mathematical understanding.

6.4. Statistical Significance in PSTs' Performance in the Assignments. Finally, a paired sample $t$-test was conducted to determine whether the change in PSTs' capacity during the two assignments was statistically significant. A paired sample $t$-test revealed a significant difference in PSTs' capacity to attend to children's strategies during the Inquiry into Student Thinking assignment (ACS) $(M=1.37$, $\mathrm{S} . \mathrm{D}=0.556)$ compared with their responses during the tutoring assignment (ACS-Tutoring) $(M=1.70, \mathrm{~S} . \mathrm{D}=0.535)$ with $t(29)=-2.763, p=0.010$. For the component skill of interpreting children's understanding (ICU), a paired sample $t$-test showed no significant difference in PSTs' capacity during the Inquiry into Student Thinking assignment $(M=1.53$, S.D $=0.629)$ compared with their responses during the tutoring assignment that revealed no significant difference $(M=1.63, \quad$ S.D $=0.615)$ with $t(29)=-0.619$ $p=0.541$. For the component skill of responding based on children's mathematical understanding, a pairwise comparison revealed that there was no significant difference between PSTs' capacity to respond during the Inquiry into Student Thinking $(M=0.87$ S.D $=0.629)$ compared with their responses during the tutoring assignment $(M=1.07$ S.D $=0.828)$ with $t(29)=-1.099, p=0.281$.

6.5. A Closer Look at the Component Skill of Responding on the Basis of Children's Mathematical Understanding. The results presented in this section inform the third research question:

What type of tasks/problems do PSTs pose after assessing children's mathematical understanding?

PSTs' responses to the following prompts in the Inquiry into Student Thinking and tutoring assignment were used:

(1) If you were to teach the next lesson to this group of students, write one problem that you could give them and explain why you think this would be a good 
problem for this group (Inquiry into Student Thinking assignment)

(2) What was your plan for this week? Describe the activities, problems, literature etc. that you planned to use during this week's tutoring session and explain your rationale for this plan. Included in your rationale should be: What makes these tasks high cognitive demand for your students? (Tutoring assignment)

The nature of instructional tasks selected and rationale of PSTs' choices, both in the Inquiry into Student Thinking and tutoring assignments, were examined.

6.5.1. Inquiry into Student Thinking Assignment. As shown in Table 7, 28 out of 30 PSTs selected word problems, one participant selected a relational thinking number sentence $(40+60=-+-)$, and one participant selected true or false sentences. PSTs used the CGI problem-type framework that was created by Carpenter et al. [49] for addition and subtraction word problems. The CGI problem type framework categorizes addition and subtraction word problems into four basic categories involving (a) joining action, (b) separating action, (c) part-part whole relations, and (d) comparison situations. The PSTs had practiced how to develop word problems using the framework in class prior to doing the assignment. Some PSTs paid specific attention to the number choices and were cognizant of numbers that would develop specific students' understanding. For example, one student created a Join Result Unknown and provided a rationale.

"Sunny has fish, and then she buys more. How many fish does she have now?" Number choices would include $\{(10,50)(20,30)(10,41)(15,25)\}$

6.5.2. Rationale of the Number Choices. This type of problem would be good for all of the students. Sunny and Daniella struggle to count by tens past the numbers 20 and 30 , and this problem challenges them to do so. Emilio would be challenged to count by tens and keep track of the 'one' in 41 . Both Jack and Emilio would be challenged by the last number choice, as both understand the concept of counting by tens, but they would.

Notable in this response is the fact that this PST selected and used number choices that would advance the children's mathematical understanding. The PST focused on how the task would support Sunny and Daniella's understanding because "they struggled to count by 10 " and both Jack and Emilio would be challenged by the last number choice because they "understand the concept of counting by 10." This type of reasoning seemed to be a tendency for PSTs even when they did not select multiple number choices. For example, one PST selected the task, "Danielle has 55 beads. She wants to make as many necklaces as she can, but she must have 10 beads on each necklace. How many complete necklaces can she make? How many beads will she have left over?" Explaining why she selected those numbers, she remarked:
I chose 55 because the students already demonstrated knowledge of knowing 50 is 5 groups of 10 and 5 is an easy number to work with as a remainder. I chose 10 because the goal is to get the students to develop and use the idea of ten as one and use it to problem solve

The examples also provide persuasive evidence that the PSTs had some capacity to choose tasks based on children's mathematical understanding by the time they did the Inquiry into Students' Thinking assignment.

6.5.3. Tutoring Assignment. To examine the nature of tasks that the PSTs selected in the tutoring assignment, PSTs' lesson plans for the first tutoring sessions were examined. Although we used PSTs' responses for the interview and the first tutoring session, PSTs had an opportunity to tutor the same child or children for three 50-minute sessions. Therefore, they got an opportunity to interpret children's mathematical understanding and select and pose tasks for three times. PSTs had been instructed to start with an opening number routine followed by the main activity, which they used to tutor the children based on the interpretation of children's mathematical understanding. As shown in Table 8,17 out of 30 PSTs selected CGI word problems, 3 out of 30 PSTs selected true or false number sentences, 3 out of 30 selected open-number sentences and equations, 5 out of 30 selected counting tasks, and 2 out of 30 selected tasks that required children to identify the place value.

Further analysis revealed four emerging patterns that characterized the rationale for the number choices and nature of problems created: (1) selected number choices that started with easier numbers to more challenging numbers, (2) considered the strategy that the children would use to solve the task, (3) considered children's understanding or how the children will make sense of the problem, and (4) no rationale to the number choices. A brief explanation of each pattern is given in the next section.

6.5.4. Selected Number Choices That Started from Easier to More Challenging Numbers. Twelve of the participants selected number choices that started with easier numbers to more challenging numbers. In this approach, the PSTs' rationales revealed a tendency to start with easier numbers that the children could manipulate with ease, followed by larger numbers that the children could not manipulate using mental strategies alone. The PSTs either referred to those first numbers as "easier numbers" or "familiar numbers." From their reasoning, "the easier" or "familiar numbers" could make the children more comfortable with the concept before working with more challenging numbers. For example, one PST selected the following task for kindergarten children:

Problem: Cornor has __Wii games in his cupboard. He found more Wii games under his bed. How many Wii games does Cornor have?

Number Choices: $(7,3)(4,6)$ 
TABLE 7: Nature of tasks selected during the Inquiry into Student Thinking assignment.

\begin{tabular}{|c|c|c|c|}
\hline Problem type & $\begin{array}{l}\text { \# of } \\
\text { tasks }\end{array}$ & PSTs example & Number choices \\
\hline Join Change Unknown & 5 & $\begin{array}{l}\text { "Joshua collects rocks. He likes to keep } \\
\text { them in bags of ten. Last week he had a } \\
\text { total of bags. After finding some } \\
\text { more this week, he now has bags. } \\
\text { How many rocks did Joshua find this } \\
\text { week?" }\end{array}$ & Number Choices: 5,6$)(5,8)(8,12)(9,15)$ \\
\hline Join Result Unknown & 8 & $\begin{array}{l}\text { I would create Joint-Result-Unknown } \\
\text { (JRU) or Separate-Result-Unknown } \\
\text { (SRU) problems for the students. A JRU } \\
\text { example would be "Sunny has _fish, } \\
\text { and then she buys more. How many } \\
\text { fish does she have now?" Number choices } \\
\text { would include }\end{array}$ & $\begin{array}{c}\text { Number Choices: }\{(10,50)(20,30)(10,41) \\
(15,25)\} .\end{array}$ \\
\hline Compare change unknown & 1 & $\begin{array}{c}\text { Emilio had } 64 \text { soccer cards. Sunny had } 28 \\
\text { soccer cards. How many more soccer } \\
\text { cards does Emilio have than sunny? }\end{array}$ & \\
\hline Separate result unknown & 4 & $\begin{array}{l}\text { Emilio has__soccer balls. __ Soccer balls } \\
\text { roll away. How many Soccer balls are left? } \\
\text { Jack has } 65 \text { pencils. He wants his } 5\end{array}$ & $\begin{array}{c}\text { Number Choices: }(15,5)(26,16)(57,27) \\
(81,51)\end{array}$ \\
\hline Group size unknown & 2 & $\begin{array}{c}\text { classmates to each have an equal amount } \\
\text { of pencils. How many would each } \\
\text { classmate get?" }\end{array}$ & No number Choices \\
\hline Number of groups unknown & 3 & $\begin{array}{c}\text { Sunny has } 94 \text { chocolate chips. She needs } \\
10 \text { chocolate chips to make a cookie. How } \\
\text { many cookies can Sunny make? }\end{array}$ & No number Choices \\
\hline $\begin{array}{l}\text { Both product unknown \& Joint Result } \\
\text { Unknown }\end{array}$ & 4 & $\begin{array}{l}\text { Sunny has } 8 \text { rolls of candy. Each package } \\
\text { has } 11 \text { candies in it. She also has } 12 \text { extra } \\
\text { candies. How many candies does she have } \\
\text { in all? }\end{array}$ & No number Choices \\
\hline $\begin{array}{l}\text { Product unknown and compare result } \\
\text { unknown }\end{array}$ & 1 & $\begin{array}{l}\text { Mary had _ bags of cookies with } \\
\text { cookies in each bag and Amy had __ bags } \\
\text { of cookies with _ cookies in each bag. } \\
\text { Which one had more cookies? }\end{array}$ & No number Choices \\
\hline Relational thinking problems & 1 & $\begin{array}{c}40+60=-+- \\
10+2=6\end{array}$ & No number Choices \\
\hline True/false sentences & 1 & $\begin{array}{c}10+5=5+10 \\
10+10+10+9=20+19\end{array}$ & No number Choices \\
\hline
\end{tabular}

James has ___ Wii games at his house. Cornor let James borrow ___more Wii games. How many Wii games does James have at his house now?

Number choices: $(5,5)(2,8)$

Rationale for number choices: I chose $(7,3)$ because it should be easier for the students to start at 7 and only count 3 up to 10. Then, I chose 4 and 6 because counting from 4 is further from 10 . I chose 5 and 5 for the second problem because I want to see if students will use their strategies or if they just know that $5+5=10$. Finally, I chose 2,8 because it is more difficult than the other three choices. The students will have to count-up 8 times to get to 10 .

From the above rationale, the PST was cognizant of the number patterns and the connections that she wanted the children to make. One PST considered numbers that were easier to challenging but paid specific attention to the way the numbers would advance children's mathematical understanding. She chose the following task for two kindergarten children and selected the number choices based on the strategies she anticipated the children to use.

Student 1(use their names in the real setting) has_race cars. Student 2 gave student $1 \_$more race cars. How many race cars does student 1 have in total?

Number choices:

Student 1 adding to $10(5,5)(7,3)(4,6)(15,5)$

Student 2 adding to $100(50,50)(80,20)(35,65)(42,58)$

To justify her number choices, the PST anticipated that children will use doubling strategy, use the "make a 10 strategy," counting from a bigger number to get to the answer, counting by 5 's, and using decade and nondecade numbers. The rationale of the number choices revealed that they were purposefully selected to progress individual students' thinking. She also considered different numbers that would sum up to 10 and 100 respectively. Although the multiple number choices could be characterized from easier 
TABLE 8: Nature of tasks selected and/or generated during the tutoring assignment.

\begin{tabular}{lcc}
\hline Type & $N \quad$ Example & Number choices \\
\hline CGI-word problems & \multirow{2}{*}{$\begin{array}{c}\text { Student 1(use their names in the real setting) has } \\
\text { race cars. How many race cars does student } 1 \\
\text { have in total? }\end{array}$} & $\begin{array}{c}\text { Student } 1 \text { adding to 10_(5, 5) 7, 3) }(4,6)(15,5) \\
\text { student 2 adding to 100 }(50,50)(80,20)(35,65) \\
(42,58)\end{array}$ \\
\hline
\end{tabular}
have in total?

Those numbers are chosen because they are

The student will be presented with these problems one at a time and they determine

True or false sentences 3 whether the problem is true or not.

$$
\begin{gathered}
4+2=6 \\
3+3=6 \\
4+2=3+3
\end{gathered}
$$
within the range of 1-10 and they are familiar

10s fact for the student. The values of the equations are slightly higher but the sum allows for more differing equations to be used. I chose this equations and numbers using low numbers in value while presenting anew concept in to make her more comfortable and confident in the use of those numbers ...

$5+8=8+5$-I chose this number because I want to see if my students understand that the number to the right is the same with the number to the left

$\begin{array}{lcc}\text { Number sentences and/or } & 3 & 5+8=8+5 \\ \text { equations } & 4+3=\mathrm{hmm}+2\end{array}$

No number choices

Counting

5 both worksheets by drawing lines from the

After the students complete the number 10 worksheet the teacher will pass out the dot-todot worksheet. Students will need to complete numbers 1-30 and 5-500 first by counting up by ones and then by 5 's. This will give the students the bases for counting so that they will be able to count the "how many objects" worksheet.

I will start by writing a two digit number on my scratch paper for both students to see e.g., 76.I will ask them to say the number and then I will I chose some two digit and three digits because point at the different digits and then ask them

Place value

2 what this number represents (prompting at this grade level students know three digit the two-digit number, I will add to digit to the end of the number making it a 3 digit three digit

$4+3=\mathrm{hmmm}+2$-I chose this number sentence because I wanted to see if the students understand that the equal sign means the same as and that both sides of the equation should add up to the same number.

up to the same number.

$$
\text { number. }
$$

Note. $N=$ number of problems.

to more challenging, the PST paid careful attention to each number.

\subsubsection{Considered Strategies That Children Would Use When} Solving a Task. Some PSTs selected tasks with number choices that would support the children to identify patterns and use specific strategies. For example, one PST created a multiplication story problem with two sets of number choices as shown below:

"Sara has _ bags of candy bars with _ in each bag. How many candy bars does Sara have?"

Number choices:

$(2,5)(2,6)(2,3)(4,5)$

$(2,10) 2,12)(4,3)(4,10)$

Rationale:
The numbers that I chose in the main activity start by doubling one number then only one of the numbers in the next set would double. I was looking to see if Hilary would see that when one number is doubled in the number set then the answer for the sets would double.

The above explanation shows that the PST paid attention to the number choices, focusing on the strategy that the students would use and anticipating that the children will recognize the pattern and use it.

6.5.6. Considered How Children Will Make Sense of the Problem. Three participants considered children's understanding and how the children would make sense of the problem. For example, one participant selected the following problem: 
You had _ cookies. Your brother ate _of your cookies. Now how many cookies do you have?

$(20,4)(30,12)(15,9)(37,11)(21,49)(33,24)$

To justify her number choices, she explained:

I chose the numbers that I did because the girls could do decade-to-decade problems but couldn't do nondecade-to-nondecade all of the time and Betty couldn't do all the decade to nondecade problems.

Again, it is notable that the PST put into consideration what the children knew as she selected the numbers (doing decade-decade) and wanted to extend that to nondecade numbers. In addition to considering students' understanding, the other two participants put into consideration how the children would make sense of the mathematical idea. For example, one PST selected the following word problem and provided the following explanation:

Mary has __ grapes and __oranges. How many grapes and oranges does she have altogether?

$(3,1)(3,3)(3,5)$

Rationale:

Started with the same number of grapes every time so that they don't have to start all over every time.

$(3,1)$-Started off adding one since these are different problem types than in the opening number routine

$(3,3)$-Stayed with the same first number to see if they can use prior knowledge from first problem to help them solve this problem. Also working on doubles.

$(3,5)$-Want to see how to start the problem

This PST chose numbers that would support children to build connections and make sense of the mathematical idea.

6.5.7. No Rationale to the Number Choices. Finally, fourteen PSTs did not provide an explanation or the reasoning behind their number choices. This group provided different number choices but there was no written rationale why they chose the numbers. For example, one student who chose the following task did not provide any rationale on the tasks used.

"After the students complete the number 10 worksheet, the teacher will pass out the dot-to-dot worksheet. Students will need to complete both worksheets by drawing lines from the numbers 1-30 and 5-500 first by counting up by 1's and then by 5 's. This will give the students the bases for counting so that they will be able to count the "how many objects" worksheet.

From the above example, the PST did not elaborate how the numbers selected might develop children's mathematical understanding. As indicated in the Discussion section, the lack of a rationale might not necessary imply that the PSTs did not have a rationale for the number choices.

\section{Discussions}

The need to design the content taught in teacher preparation programs to ensure that PSTs are equipped with knowledge, skills, and practices to become well-prepared beginning teachers is of prime importance. Although the mathematics education community have highlighted lingering challenges in teacher preparation programs, the need for high-quality teachers in K-12 classrooms has been and remains imperative $[8-10,13]$. Some educators, e.g., [28], have argued that the curriculum for teacher preparation needs to be reorganized around a set of core practices and help novices develop emerging professional identities around the practices. Consequently, there is an urgent call for teacher educators to change the way they prepare PSTs $[4,5,50]$. In fact, National Mathematics Advisory Panel [50] suggests that the "outcomes of different approaches should be evaluated by using reliable and valid measures of their effects on prospective and current teachers' instructional techniques ... p. 20." This study examined (1) the extent to which PSTs developed the capacity to attend to children's strategies and interpret and respond based on children's mathematical understanding through a narrow scope of two scaffolded assignments as they go through the mathematics methods course, (2) the extent to which the rationale of PSTs' choices of instructional tasks was based on children's mathematical understanding, and (3) the nature of tasks/problems that PSTs posed after assessing children's mathematical understanding.

The results in this study indicate that PSTs' reflections evidenced emerging understanding of what it means to attend to children's strategies and interpret and respond based on children's mathematical understanding, consistently in the context of the two scaffolded assignments. Specifically, there was significant difference in the evidence noticed in attending to children's strategies during the two assignments. As Van Zoest and Stockero [37] indicated, using "carefully designed synergistic scaffolds" (p. 1) could possibly provide PSTs with more opportunities to learn than what they could have learned from one scaffold. The study contributes to teachers' understanding on the role scaffolded activities might play in developing PSTs' knowledge and practices of using children's understanding when planning for instruction.

These findings are noteworthy and encouraging in light of other studies (e.g., [21]) which reported that prospective teachers' narratives mostly had limited or no evidence of attending to children's strategies, limited or no evidence of interpreting children's mathematical understanding, and has limited or no evidence that the response was based on children's mathematical understanding. As noted in the findings, PSTs' responses demonstrated emerging understanding of attending to children's strategies and interpreting and responding on the basis of children's mathematical understanding. These findings expand on other studies that have reported that expertise of attending to children's strategies and interpreting and responding based on children's mathematical understanding can be learned [21, 31]. Specifically, Jacobs et al. [21] reported that 
the expertise of attending to children's strategies "grew with teaching experience and continued to grow with two years of professional development" (p. 14). Although it may be premature to suggest that PSTs can independently provide robust evidence, this study provides evidence that the expertise of attending to children's strategies and interpreting and responding based on children's mathematical understanding can develop in the context of scaffolded activities in a mathematics methods course.

In addition, the findings from this study provide insights to the growing body of research that have focused on identifying core practices that PSTs can learn and develop the curriculum around those practices [8, 51]. Since "learning more about students and about teaching" is a high leverage practice, we argue that teacher educators should provide more opportunities to PSTs to practice how to respond after analyzing students' understanding. Teacher educators should shift from discussing how PSTs might respond as teachers to actually allowing them to assume the role of a teacher in supervised contexts as they receive feedback. These opportunities might provide insights to possibilities and limitations of pedagogies of enactment in teacher preparation program that need to be addressed.

Furthermore, this study provides important insights on the hypothesized theoretical trajectory of professional noticing of children's mathematical understanding. Jacobs et al. [21] conceptualized the three component skills as interrelated skills where attending to children's strategies should influence the PSTs' interpretation of children's understanding and eventually influence how teachers respond based on children's mathematical understanding. As shown in Figure 2, this study provides an initial picture depicting that learning the three-component skill might not be straightforward. Pedagogically, it might be possible for PSTs to interpret children's mathematical understanding even if one has not attended to children's strategies. Although teachers develop the component skills through the interdependent relationship, we speculate that it is possible for some teachers to develop capacity to attend to children's strategies and interpret and respond based on children's mathematical understanding independently.

7.1. Nature of Instructional Task. Over time, researchers have emphasized that students learn from the kind of work that they do during class [52-58]. Inherent in this literature is the fact that mathematical tasks influence what students learn in mathematics classrooms and teachers should select or generate meaningful mathematical task. In this study, PSTs' practices of selecting or generating tasks on the basis of children's understanding are examined. The results revealed that PSTs generated story problems in the Inquiry into Student Thinking with careful attention to how the students will engage with the tasks. In particular, PSTs paid attention to how Sunny, Danielo, Jack, and Emilio solved problems and selected tasks that would meet their individual needs. These results provide persuasive evidence that PSTs had emerging capacity to choose tasks based on children's mathematical understanding by the time they did the Inquiry into Student Thinking assignment.

These findings extend what we know about PSTs' problem-posing strategies using the context of letter writing [59-61]. Specifically, Crespo [59] reported PSTs' problem-posing strategies changed "from traditional single steps and computational problems to problems that required multiple steps, open ended, exploratory and were cognitively more complex" (p. 1). In this study, PSTs created word problems using CGI framework, true or false number sentences, number sentences and equations, and counting tasks and tasks that required children to identify the place value in the tutoring assignment. Further scrutiny of PSTs' responses reveals that most participants selected tasks with careful attention to the number choices, and some PSTs selected multiple number choices that would provide the children with opportunities to extend, challenge, and advance their thinking. In their explanations, we noted some aspects of anticipating students' responses as they discussed the strategies that they expected the students to use. Since this study did not focus on how children solved the selected problem, more research on children's interactions with the problems selected would provide more insights. Overall, we argue that teacher educators might need to provide assistance to PSTs as they learn how to select and facilitate tasks that would support students' learning.

\section{Conclusions}

Based on the benefits of using children's mathematical thinking in mathematics classroom, teacher educators should consider how to decompose the practice and carefully provide PSTs with opportunities to learn in the mathematics methods course [18, 19, 22, 24, 26, 49]. As AMTE [4] indicates, "well-prepared beginning teachers must understand-at least at an initial level-how to assess the understandings and competencies of their students and use this knowledge to plan and modify instruction using research-based instructional strategies" (p. 7). If teacher educators are going to support beginning teachers to understand and be skillful in this competency, PSTs need opportunities to experience and learn how to use children's mathematical understanding as they plan for instruction. The two assignments described in this study include the objectives, the prompts used, and the analyzed data from the two time periods. As such, they can be modified and implemented by other teacher educators in other contexts.

We propose that teacher educators need to purposefully choose what to teach, how to teach, and the activities to use as they develop PSTs' capacity to attend and interpret and respond based on children's mathematical understanding. As Jacobs et al. [24] indicate, the decisions that are made either in professional development or in teacher preparation program about the focus and content to be taught can determine what the PSTs and in-service teachers will learn. As this study attempted to show, teacher educators should purposefully choose intervention activities that facilitate PSTs' learning. 


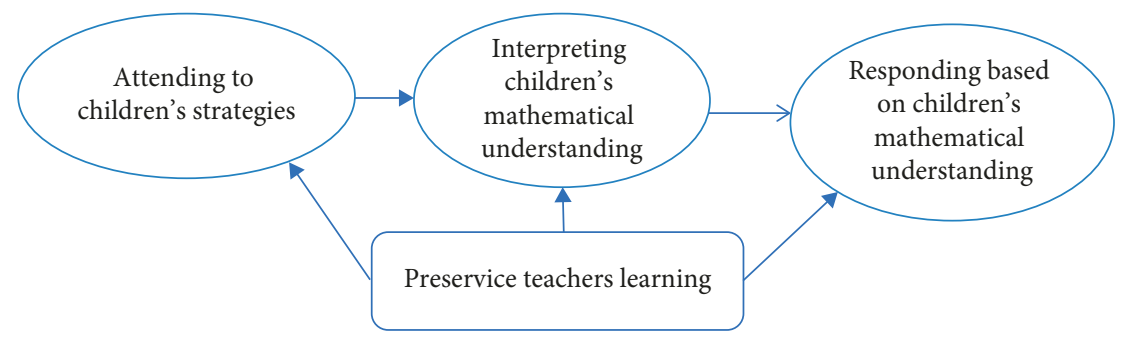

FIGURE 2: Model for PSTs' learning of the component skills of professional noticing of Children's mathematical understanding.

However, we cautiously interpret the results in this study in case we underestimate or overestimate what teacher candidates can/or cannot do as beginning teachers. Although reflections have been used to evaluate PSTs' learning, it is possible that PSTs might have responded based on children's mathematical understanding but not necessarily documented their decision-making process in the analyzed reflections. On the other hand, we might be overestimating PSTs' ability in case they mirrored the kind of tasks that they had discussed in the university classroom. Despite these limitations, many teacher educators use PSTs' reflections as a measure of learning as they go through the teacher preparation program. Additionally, to complete Educators Teacher Performance Assessment (edTPA) https://www. edtpa.com/, teacher candidates submit written work and unedited videos that are used to determine what they know and can do as beginning teachers. Thus, we are persuaded that written reflections can be used to interpret what PSTs learn as they go through the teacher preparation program.

Undoubtedly, more research is needed to determine activities that develop the component skill of responding based on children's mathematical understanding in the context of a methods course, given that the activities provided in this study did not significantly develop the component skill in all PSTs. Since we used thirty PSTs in this analysis, a future study conducted in multiple contexts and a larger sample might provide more insights into PSTs learning. Furthermore, a future study could also track how PSTs would respond as they progress to student teaching experience and as first year teachers to document how their capacity changes in different contexts. Although previous research has suggested that developing the skill of responding to children's understanding takes long to develop, teacher educators cannot underestimate the need to equip PSTs with competencies to become well started off teachers. It is hoped that the knowledge generated by this study will promote further discussions about how PSTs learn, and more activities will be shared and considered in mathematics teacher education.

\section{Appendix}

\section{A. Assignments}

A.1. Inquiry into Student Thinking. For this assignment, your primary source of information will be a case study of four second graders found at http://www.edb.utexas.edu/empson (click on "Case Study: Four Second Graders under "Categories").

Read through the entire case study first to get an idea what it is about. Then, answer the following questions in a total of 2-3 double-spaced pages:

(1) Choose one of the four students from the case study and trace their responses and learning through the study.

(a) Summarize what you think they knew or understood at the end of the study that they did not know or understand in the beginning.

(b) Choose 2 examples of this student's responses as evidence for your claim from part 1.a and explain how they support your claim about this student's learning (you will probably want one example toward the end of the study and one example toward the beginning).

(2) Choose 2 tasks or problems that were posed to the students that seemed particularly productive for advancing the thinking of the students as a group. For each problem, provide evidence from at least two of the four students to support your claim that these were productive tasks. Conjecture (i.e., make an educated guess) why these were productive tasks or problems.

(3) Choose one instance of teacher decision-making or reflection that was particularly interesting or surprising to you. Summarize in a paragraph what made that instance stand out for you and how you might use it to inform your own tutoring experience.

(4) If you were to teach the next lesson to this group of students, write one problem that you could give them and explain why you think this would be a good problem for this group. Use what you have learned in class about problem types, number choices, and students' solution strategies to support your decision.

A.2. Tutoring Assignment (Standard Assessment for Mathematics Methods Course). For this assignment, you will first interview up to three students about their understanding of numbers and operations. You will be provided with gradeappropriate questionnaires for this interview. Based (at least in part) on what you learn in the interview, you will plan and implement three tutoring sessions with these students. You 
will use Opening Number Routines and CGI story problems during your tutoring sessions. These will be tailored to target the specific goals you devised for the students. You will then analyze the student work and your own teaching. You must use the frameworks learned in the course as tools in analyzing your work with the students. In particular, you must use Levels of Cognitive Demand, Common Core Standards, CGI problem types, and CGI student solutions strategies.

\section{Part I: First Interview}

\section{Writing a Summary/Analysis of the Initial Interviews}

(1) Briefly describe the setting of the interview and the interviewed students. Remember to use PSEUDONYMS instead of students' actual names!

(2) For each of the questions on the provided interview, describe what your chosen student's responses looked like and sounded like. Identify the CGI strategy he/she used or it seems liked she/he tried to use (modeling, counting, derived facts, and invented algorithms). Remember that you might see variations on strategies as well as combinations from other things they have learned.

(3) Use the interview data as evidence in answering these questions:

(a) What does your chosen student know/think/ understand about number, operations, and problem solving? Think about what strategies or problem types they DO know and which they are on the verge of learning but have not yet learned. Be VERY specific. You must back up your claims with SPECIFIC EVIDENCE of children's words/actions.

(b) Based on your answers to part a, what specific mathematics will you focus on with these students? How will what you learned in the interviews influence how you work with these children during the next sessions?

\section{Part II: Tutoring}

Preparing to Tutor. You will tutor your student(s) two times after the first interview. The tutoring sessions must include an opening number routine activity and CGI-type problems. Use the lesson plan format described in our course. The second plan will probably be a modification (sometimes slight, sometimes not, depending on your assessment of the first tutoring session) of the first lesson plan. Check your plans with your colleagues and your instructor.

Tutoring. There is a lot to think about while you are teaching/tutoring. First, you will be thinking about what you are doing and saying-you want to follow your lesson plan but also be flexible based on your formative assessments of what your students are and are not understanding. During each session, you will also want to pay close attention to your students' thinking-their strategies, responses (correct and incorrect), questions, etc.

Remember that your students should be doing the bulk of the talking. They are the ones doing the mathematics. You will be unpacking the problem, asking questions, planning the sharing of solutions, and doing some rephrasing. If you find yourself explaining most of the time, you are doing it wrong.

\section{Writing Up Your Tutoring Sessions}

After each tutoring session, complete a write-up addressing the following:

(1) What was your plan for this week?

Include your Lesson Plan and explain:

(a) What makes these tasks high cognitive demand? Use the criteria from the packet to justify your answer.

(b) How are these tasks intended to build on what you already know about your student's understandings and misunderstandings? Here justify your Opening Number Routine, story problems types, and number choices. Why did you choose the numbers/ problems/activities you did?

(2) What actually happened during your tutoring session this week?

Describe IN DETAIL what happened during your lesson-what you said and did, what your focus student said and did, what CGI strategies you observed students using, what questions students had. Do not just say, "I followed the lesson plan." Instead, provide SPECIFIC descriptions of what you and the students said or did-especially the strategies your student used and how you responded to those strategies. Include major decisions you made while teaching. What types of mathematical issues arose that were unexpected? What range of strategies did students use? How did you organize and assist their explanations of their strategies?

(3) How effective were your plan and your teaching? What did your assessment plan tell you about your students' growth, and what did not they tell you about your students? Provide specific evidence of what the students said and did to support your answer to this question.

(4) What do you still wonder about your students and their mathematical thinking?

(5) What will you focus on during the next session, and why?

\section{Part III: Reflecting On Your Experience}

Finally, spend some time reflecting on this experience. Use data from your interview and tutoring session to justify your answers. There should be a lot of sentences that look 
like "I know this because the student ..." Also, focus on the mathematics, rather than behavior or other issues. This reflecting piece should be used as part of your e-portfolio synthesis of evidence. In particular, address the following questions:

(i) What did you learn about learning, teaching, mathematics, and students during this experience? Address here how this assignment helped you with Standard Four, which states, "The candidate plans instruction based upon knowledge of subject matter, students, the community, curriculum goals, and state curriculum models."

(ii) How do your original goals for the tutoring sessions compare with what really happened?

(iii) Overall, how do you feel your interviews and tutoring sessions went?

(iv) What would you do next with these students?

(v) How can you use this process in your own teaching?

\section{Data Availability}

Data used to support the findings of this study are included within the article. However, any supplemental tables and analyzed data from responses to the Inquiry into Student Thinking assignment and the tutoring assignment are available from the corresponding author upon request.

\section{Disclosure}

This manuscript is based on a larger unpublished graduate thesis and dissertation by authors, currently in the Iowa State University digital repository that examined elementary preservice teachers' capacity to use children's mathematical understanding to select and pose mathematical tasks at "https:// lib.dr.iastate.edu/cgi/viewcontent.cgi? referer=\&httpsredir $=1 \&$ article $=4433 \&$ context $=$ etd. $"$

\section{Conflicts of Interest}

The authors declare that they have no conflicts of interest or funding sources to disclose.

\section{Acknowledgments}

The authors thank Corey Drake, Susan Gallagher-Lepak, and Scott Ashmann for their feedback on different versions of this article. The authors also sincerely appreciate the preservice teachers who agreed to participate in this study. This work would not have been feasible without their contribution.

\section{References}

[1] M. Allen, Eight Questions on Teacher Preparation: What Does the Research Say?, Education Commission of the States, Denver, CO, USA, 2003.

[2] S. Blömeke, F.-J. Hsieh, G. Kaiser, and W. H. Schimidt, International Perspectives on Teacher Knowledge Beliefs and Opportunities TEDS-M Results, Springer, Berlin, Germany, 2014.
[3] Conference Board of Mathematical Sciences (CBMS), The Mathematics Education for Teacher II Issues in Mathematics Education, vol. 17, American Mathematical Society and Mathematical Association of America, Providence, RI, USA, 2012.

[4] Association of Mathematics Teacher Educators (AMTE), Standards for Preparing Teachers of Mathematics, 2017, http:// amte.net/standards.

[5] National Council for Accreditation of Teacher Education (NCATE), Transforming teacher education through clinical experience: A national strategy to prepare effective teachers Report of the Blue-Ribbon Panel on Clinical Preparation and Partnership for Improved Student Learning, 2010, http://www. ncate.org/.

[6] M. E. Strutchens, R. Huang, L. Losano, and D. Potari, The Mathematics Education of Prospective Secondary Teachers Around the World, Springer International Publishing AG Switzerland, Cham, Switzerland, 2016.

[7] M. T. Tatto, J. Schwille, S. Senk, L. Ingvarson, R. Peck, and G. Rowley, "Teacher Education and Development Study in Mathematics (TEDS-M): policy, practice, and readiness to teach primary and secondary mathematics," in Conceptual Framework, Teacher Education and Development International Study Center, College of Education, Michigan State University, East Lansing, MI, USA, 2008.

[8] D. Ball, L. Sleep, T. Boerst, and H. Bass, "Combining development of practice and the practice of development of teacher education," Elementary School Journal, vol. 109, no. 5, 2009.

[9] M. Cochran-Smith and K. Zeichner, Studying Teacher Education: The Report of AERA Panel on Research and Teacher Education, American Educational Research Association Lawrence Erlbaum Associates, Inc., Washington, DC, USA, 2005.

[10] P. Grossman and M. McDonald, "Back to the future: directions for research in teaching and teacher education," American Educational Research Journal, vol. 45, no. 1, pp. 184-205, 2008.

[11] J. Hiebert and A. K. Morris, "Building a knowledge base for teacher education: an experience in K-8 mathematics teacher preparation," Elementary School Journal, vol. 109, no. 5, pp. 475-490, 2009.

[12] M. McDonald, E. Kazemi, and S. S. Kavanagh, "Core practices and pedagogies of teacher education," Journal of Teacher Education, vol. 64, no. 5, pp. 378-386, 2013.

[13] A. K. Morris, J. Hiebert, and S. Spitzer, Mathematics Knowledge for Teaching and Planning and Evaluating Instruction: What Can Pre-Service Teachers Learn?, The National Council of Teachers of Mathematics, Inc., Reston, VA, USA, 2009, http://www.nctm.org.

[14] T. G. Bartell, C. Webel, B. Bowen, and N. Dyson, "Prospective teacher learning: recognizing evidence of conceptual understanding," Journal of Mathematics Teacher Education, vol. 16, no. 1, pp. 57-79, 2013.

[15] A. R. McDuffie, M. Q. Foote, C. Bolson et al., "Using video analysis to support prospective K-8 teachers' noticing of students' multiple mathematical knowledge bases," Journal of Mathematics Teacher Education, vol. 17, pp. 245-270, 2013.

[16] J. R. Star and S. K. Strickland, "Learning to observe: using video to improve preservice mathematics teachers' ability to notice," Journal of Mathematics Teacher Education, vol. 11, no. 2, pp. 107-125, 2008.

[17] D. Teuscher, K. R. Leathan, and B. Peterson, "From a framework to a lens: learning to notice students mathematical 
thinking," in Teacher Noticing: Bridging and Broadening Perspectives, Contexts, and Frameworks, O. Schack, M. H. Fisher, and J. A. Wilhelm, Eds., Springer International Publishing AG, Basel, Switzerland, 2017.

[18] L. S. Shulman, "Those who understand teaching: knowledge growth in teaching," Educational Researcher, vol. 57, no. 1, pp. 1-22, 1986.

[19] R. Marks, "Pedagogical content knowledge: from a mathematical case to a modified conception," Journal of Teacher Education, vol. 41, no. 3, pp. 3-11, 1990.

[20] T. Carpenter, E. Fennema, and M. Franke, "Cognitively guided instruction: a knowledge base for reform in primary mathematics instruction," Elementary School Journal, vol. 97, no. 1, pp. 3-20, 1996.

[21] V. R. Jacobs, L. C. Lamb, and R. A. Philipp, "Professional noticing of children's mathematical thinking," Journal of Research in Mathematics Education, vol. 41, no. 2, pp. 169202, 2010.

[22] M. L. Franke, E. Kazemi, and D. Battey, "Understanding teaching and classroom practice in mathematics," in Second Handbook of Research on Mathematics Teaching and Learning, F. Lester Jr., Ed., pp. 225-256, Information Age, Charlotte, NC, USA, 2007.

[23] M. Franke and E. Kazemi, "Learning to teach mathematics: focus on students thinking," Theory into Practice, vol. 40, no. 2, pp. 102-109, 2001.

[24] V. R. Jacobs, M. L. Franke, T. P. Carpenter, L. Levi, and D. Battey, "Professional development focused on children's algebraic reasoning in elementary schools," Journal for Research in Mathematics Education, vol. 38, no. 3, pp. 258-288, 2007.

[25] A. Sfard and C. Kieran, "Cognition as communication: rethinking learning-by-talking through multi-faceted analysis of students' mathematical interactions," Mind, Culture, and Activity, vol. 8, no. 1, pp. 42-76, 2001.

[26] J. Fraivillig, "Strategies for advancing children's mathematics understanding," Teaching Children Mathematics, vol. 7, no. 8, pp. 1-6, 2001.

[27] T. Barnhart and E. Van Es, "Studying teacher noticing: examining the relationship among pre-service science teachers' ability to attend, analyze and respond to student thinking," Teaching and Teacher Education, vol. 45, pp. 83-93, 2015.

[28] P. Grossman, C. Compton, D. Igra, M. Ronfeldt, E. Shahan, and P. W. Williamson, "Teaching practice: a crossprofessional perspective," Teachers College Record, vol. 111, no. 9, pp. 2055-2100, 2009.

[29] J. Mason, Researching Your Own Practice: The Discipline of Noticing, Routledge-Falmer, London, UK, 2002.

[30] V. R. Jacobs and R. C. Ambrose, "Making the most of the story problems," Teaching Children Mathematics, vol. 15, pp. 260266, 2008.

[31] M. Sherin and E. Van Es, "Using videos to support teachers' ability to notice teachers' interactions," Journal of Technology and Teacher Education, vol. 13, no. 3, 2005.

[32] E. Van Es and M. Sherin, "How different video club designs support teachers in learning 'to notice'," Journal of Computing in Teacher Education, vol. 22, pp. 571-596, 2007.

[33] J. Kaste, "Scaffolding through cases: diverse constructivist teaching in the literacy methods course," Teaching and Teacher Education, vol. 20, article 31e45, 2004.

[34] L. S. Vygotsky, Mind in Society, Harvard University Press, Cambridge, MA, USA, 1978.
[35] D. Wood, J. S. Bruner, and G. Ross, "The role of tutoring in problem solving," Journal of Psychology and Psychiatry, vol. 17, no. 2, pp. 89-100, 1976.

[36] L. Sleep and T. Boerst, "Preparing beginning teachers to elicit and interpret students' mathematical thinking," Teaching and Teacher Education, vol. 28, no. 7, pp. 1038-1048, 2011.

[37] L. Van Zoest and S. Stockero, "Synergistic scaffolds as a means to support pre-service teacher learning," Teaching and Teacher Education, vol. 23, no. 8, pp. 2038-2048, 2008.

[38] D. Holton and D. Clarke, "Scaffolding and metacognition," International Journal of Mathematical Education in Science and Technology, vol. 37, no. 2, pp. 127-143, 2006.

[39] I. Tabak, "Synergy: a complement to emerging patterns of distributed scaffolding," Journal of the Learning Sciences, vol. 13, no. 3, pp. 305-335, 2004.

[40] S. Empson, "Responsive teaching from the inside out: teaching base ten to younger children," Investigations in Mathematics Learning, vol. 7, no. 1, pp. 23-53, 2014.

[41] N. Golafshani, "Understanding reliability and validity in qualitative research," Qualitative Report, vol. 8, no. 4, pp. 597-607, 2003.

[42] H. K. Klein and M. D. Myers, "A set of principles for conducting and evaluating interpretive field studies in information systems," MIS Quarterly, vol. 23, no. 1, pp. 67-94, 1999.

[43] G. Walsham, "Interpretive case studies in IS research: nature and method," European Journal of Information Systems, vol. 4, no. 2, pp. 74-81, 1995.

[44] M. T. H. Chi, "Quantifying qualitative analyses of verbal data: a practical guide," Journal of the Learning Sciences, vol. 6, no. 3, pp. 271-315, 1997.

[45] M. Miles and A. M. Huberman, Qualitative Data Analysis, SAGE, Thousand Oaks, CA, USA, 2nd edition, 1994.

[46] M. S. Smith and M. K. Stein, "Selecting and creating mathematical tasks: from research to practice," Mathematics Teaching in Middle School, vol. 3, pp. 344-350, 1998.

[47] M. K. Stein and M. S. Smith, "Mathematical tasks as a framework for reflection: from research to practice," Mathematics Teaching in the Middle School, vol. 3, no. 4, pp. 268-275, 1998.

[48] J. Creswell and D. Miller, "Determining validity of qualitative research," Theory into Practice, vol. 39, no. 1, 2000.

[49] T. P. Carpenter, E. Fennema, M. L. Franke, L. Levi, and S. B. Empson, Children's Mathematics: Cognitively Guided Instruction, Heinemann, Portsmouth, NH, USA, 1999.

[50] National Mathematics Advisory Panel, Foundations for Success: The Final Report of the National Mathematics Advisory Panel, U.S. Department of Education, Washington, DC, USA, 2008.

[51] P. Grossman, K. Hammerness, and M. McDonald, "Redefining teaching, re-imagining teacher education," Teachers and Teaching, vol. 15, no. 2, pp. 273-289, 2009.

[52] M. Henningsen and M. K. Stein, "Mathematical tasks and student cognition: classroom-based factors that support and inhibit high-level mathematical thinking and reasoning," Journal for Research in Mathematics Education, vol. 28, no. 5, pp. 524-549, 1997.

[53] J. Hiebert, T. P. Carpenter, E. Fennema et al., Making Sense: Teaching and Learning Mathematics with Understanding, Vol. 361, Heinemann, Portsmouth, NH, USA, 1997.

[54] J. Hiebert and D. Wearne, "Instructional tasks, classroom discourse, and students' learning in second-grade Arithmetic," American Educational Research Journal, vol. 30, no. 2, pp. 393-425, 1993. 
[55] J. Houssart, "Simplification and repetition of mathematical tasks: a recipe for success or failure?," Journal of Mathematical Behavior, vol. 21, no. 2, pp. 191-202, 2002.

[56] National Council for Teachers of Mathematics, Principals and Standards for School Mathematics, Reston, VA, USA, 2000.

[57] M. K. Stein, M. S. Smith, M. A. Henningsen, and E. A. Silver, Implementing Standards Based Mathematics Instruction: A Casebook for Professional Development, Teachers College Press, New York, NY, USA, 2000.

[58] A. J. Stylianides and G. J. Stylianides, "Studying the classroom implementation of tasks: high-level mathematical tasks embedded in 'real-life' contexts," Teaching and Teacher Education, vol. 24, no. 4, pp. 859-875, 2008.

[59] S. Crespo, "Learning to pose mathematical problems: exploring changes in pre-service teachers practices," Educational Studies in Mathematics, vol. 52, no. 3, pp. 243-270, 2003.

[60] A. Norton and Z. Rutledge, "Measuring task posing cycles: mathematical letter writing between algebra students and preservice teachers," Mathematics Teacher Educator, vol. 19, no. 1, pp. 32-45, 2006.

[61] Z. Rutledge and N. Norton, "Pre-service teachers mathematical task posing: an opportunity for coordination of perspectives," Mathematics Educator, vol. 18, no. 1, pp. 31-40, 2008. 


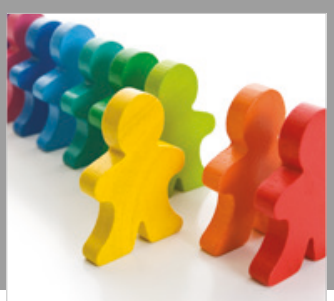

Autism

Research and Treatment
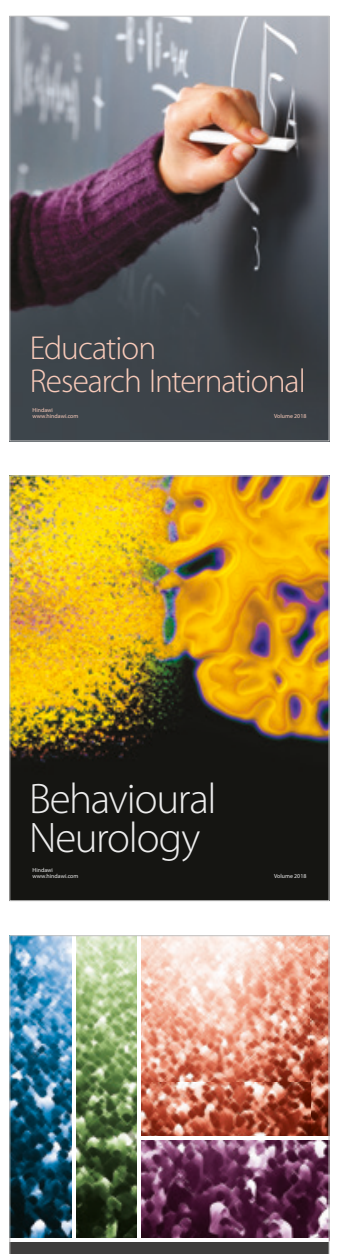

International Journal of

Population Research

$\underline{-m}$

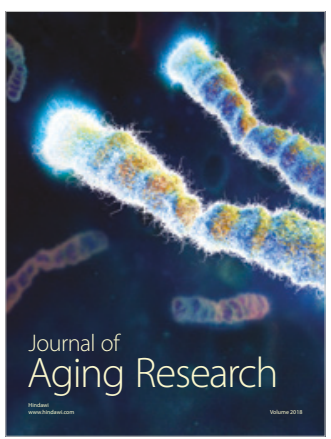

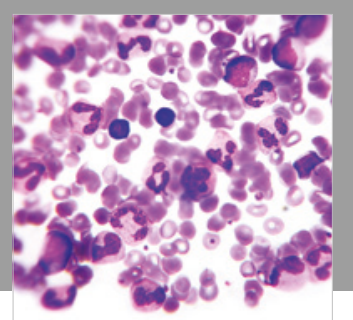

Pathology

Research International$$
=
$$

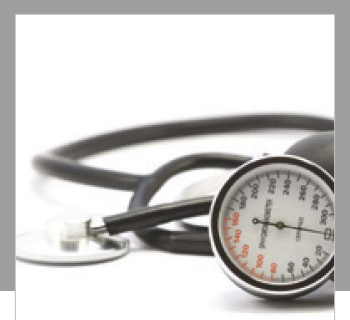

Nursing

Research and Practice

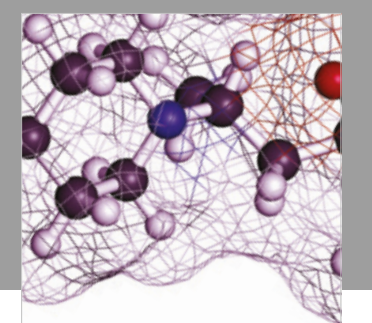

Pain

Research and Management

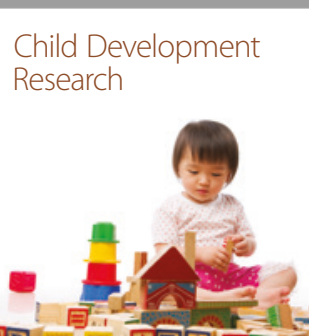

बाD

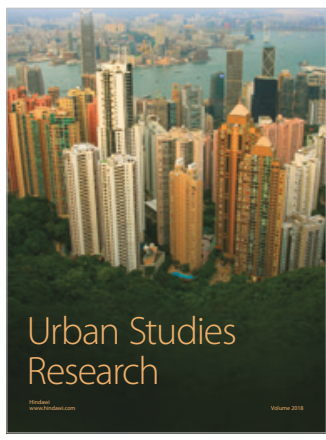

\section{Hindawi}

Submit your manuscripts at

www.hindawi.com
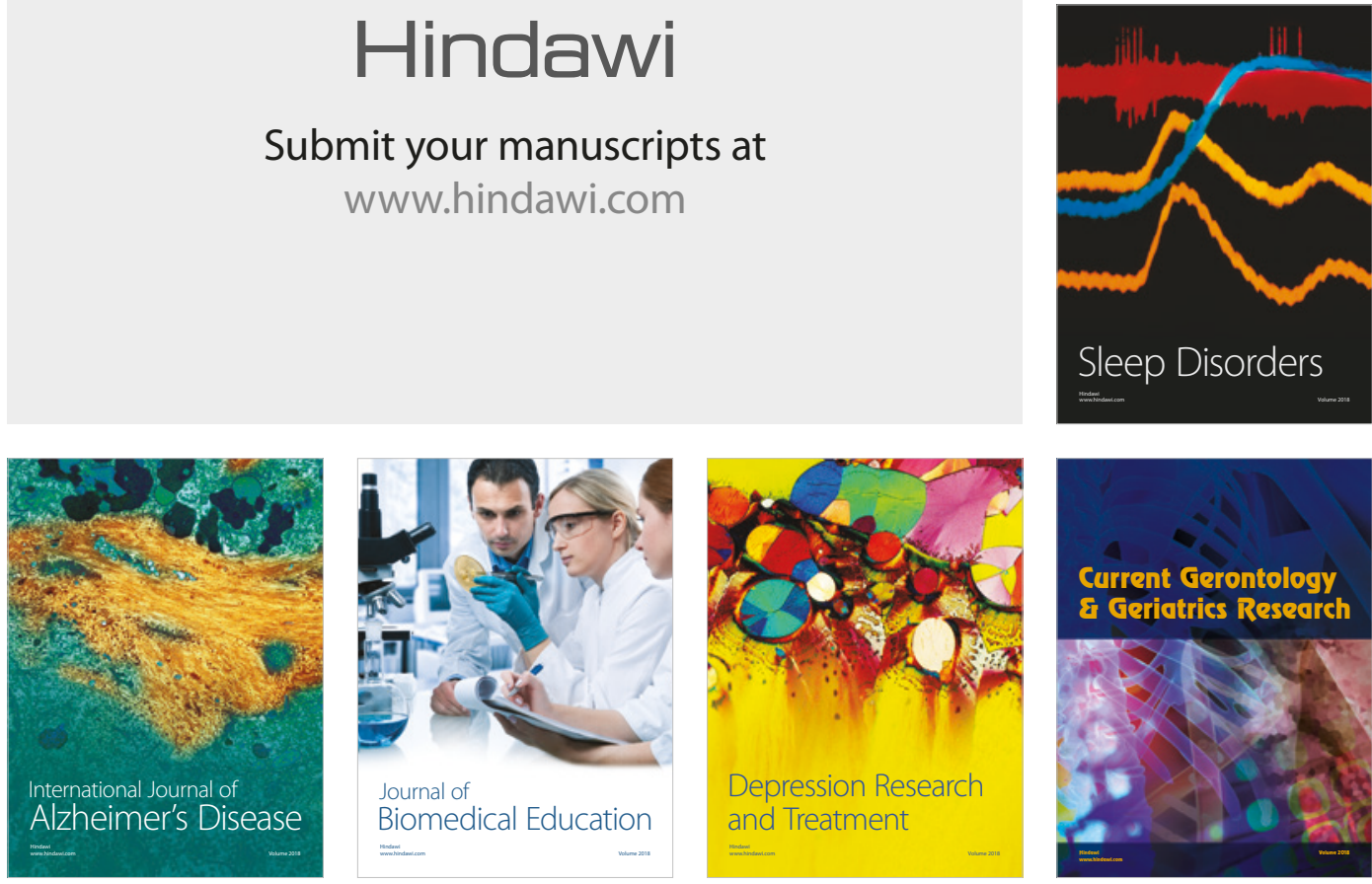

Journal of

Biomedical Education

$=$

smman

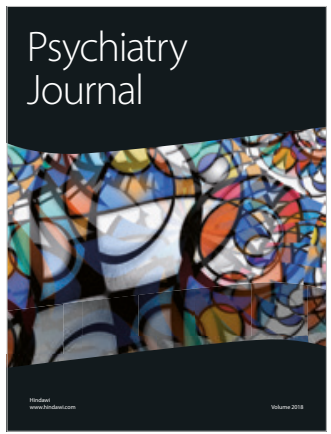

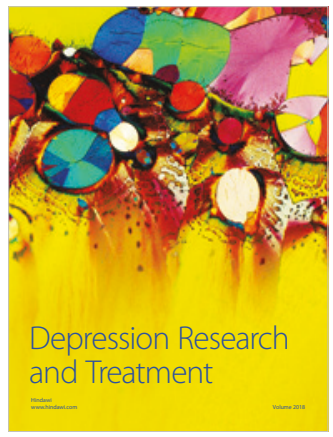
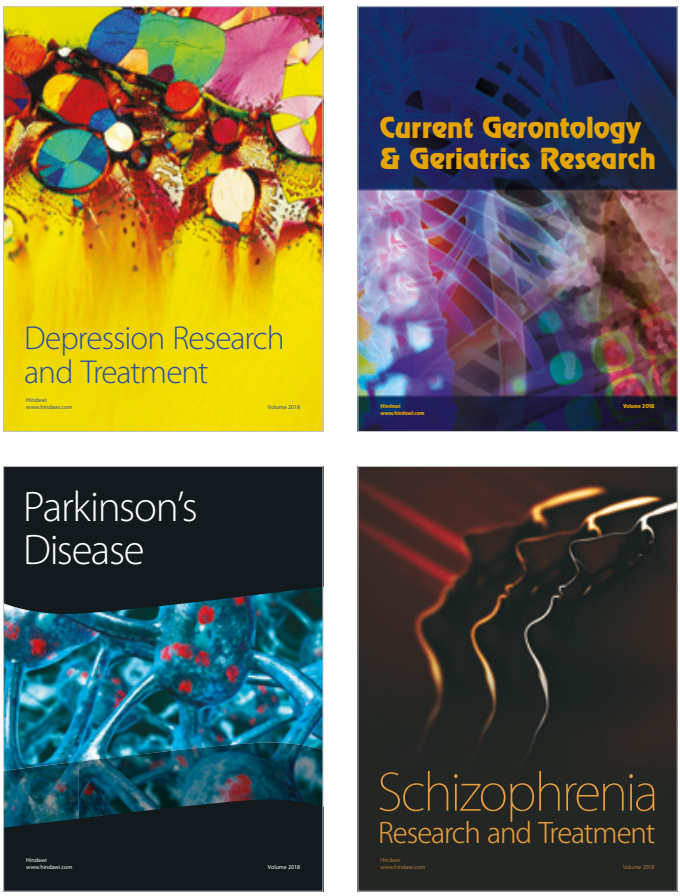